\title{
Reflexes of ${ }^{*} r$ and ${ }^{*} l$ in 'Caland' Formations
}

\section{Introduction}

In chapter 2, it was argued that an analogical account of the vocalism of $\tau \dot{\varepsilon} \tau \alpha \rho-$

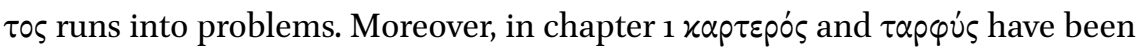
identified as problematic forms for the idea that $-\rho \alpha$ - is the regular reflex of word-internal ${ }^{*} r$ in Ionic-Attic. I therefore hypothesize that the regular IonicAttic reflex is $-\alpha \rho$-. This means that a considerable number of forms with $-\rho \alpha-<$ ${ }^{*} r$ must be accounted for. This is the objective of chapters 4 till 9 .

Within this context, it is of the utmost importance to systematically examine the analogical processes that may have influenced forms with - $\rho \alpha$ - and - $\alpha \rho-$. In this chapter, I discuss forms with - $\rho \alpha$ - and - $\alpha \rho$ - belonging the so-called 'Caland system.' I will first give a descriptive overview of this system from a Greek point of view, focusing on reconstructible ablaut patterns (section 4.1) and the productivity of derivations (section 4.2). After that, a detailed account of the reflexes of ${ }^{*} r$ and ${ }^{*} l$ in individual formations, notably $u$-stem adjectives (sec-

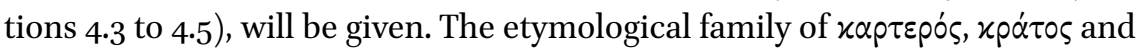
related forms is treated separately in chapter 5 .

\subsection{The Root Vocalism of 'Caland' Formations in Greek and PIE}

According to Caland's original formulation of the phenomenon that bears his name, Indo-Iranian adjectives in -ra-, -ma-, or -ant- replace these suffixes with $-i$ - when appearing as a first compound member. ${ }^{2}$ Caland's prime examples from Avestan included darazra- 'firm' beside darazi-ra $\vartheta a$ - 'having a firm chariot', and xrūra- 'bloody' beside xruui-dru- 'having a bloody weapon'. Wackernagel (1897) then extended the substitution rule from Indo-Iranian to

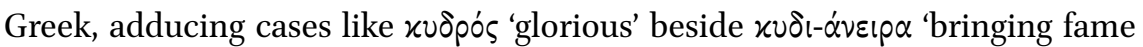
to men'. Crucially, he argued that the phenomenon is inherited from PIE in

1 For introductions to the Caland system of derivational morphology, the reader is referred to Meissner (2006) and Rau (2009).

2 The following paragraphs on the history of scholarship on Caland's Law and the Caland system closely follow Meissner's overview (2006: 14-16). See there for a full discussion of all scholars who significantly contributed to the subject. 
view of the equation Ved. rji-śvan- PN "who has swift dogs" beside àpүl-xźpavvos

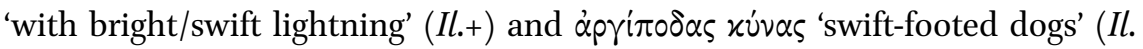

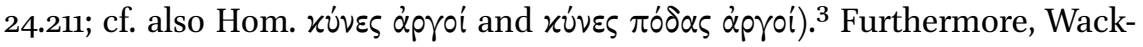
ernagel remarked that other suffixes participated in the alternation as well:

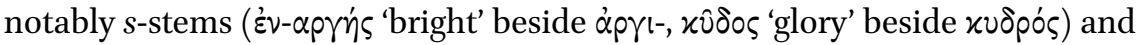
$u$-stem adjectives (Ved. rjú- 'straight' beside rji-pya- 'flying straight', epithet of the eagle). ${ }^{4}$

Although the use of * $i$ - as a compounding allomorph of *-ro- played a key role in the discovery of 'Caland' morphology, this archaic substitution rule has lost its central place in more recent discussions. Scholars like Risch and Nussbaum have stressed that 'Caland' morphology is primarily a system of regularly alternating affixes that must be studied as a historically developing entity, with its own dynamics in the individual languages. Thus, Meissner speaks of the 'Caland system' as a "regular and well-defined set of correspondences of derivational affixes" (2006: 3$).{ }^{5}$ What is remarkable about these correspondences is that roots which combine with 'Caland suffixes' do not normally take other derivational suffixes ( such as $^{*}-t i-{ }^{*}{ }^{*}-m n-$ ).

In Greek, a model 'Caland system' consists of a primary adjective (often in -v́s or -pós, though other suffixes are possible too), forms of comparison in -i $i \omega \nu$ and $-\iota \tau \tau \varsigma$, compounded adjectives in $-\eta \varsigma$, and a neuter noun in - $0{ }^{6}{ }^{6}$ Sometimes, a compounding first member in -l- is found. Thus, the following Greek forms containing the root $x \cup \delta$ - are attested:

- Adj. xvo-pós

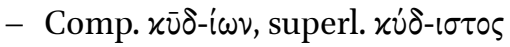

- Neuter abstract $x \hat{\delta} \delta$ -

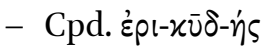

- Cpd. $x \bar{\nu} \delta--\imath-\alpha ́ v \varepsilon i \rho \alpha$.

3 Wackernagel also claimed that ג̇pyó soriginated from *arg-ró- by dissimilation; this has in more recent times been doubted by Nussbaum; see Vine (2011) for discussion.

4 As Meissner (2006: 11-14) shows, this discovery had already been made by Parmentier (1889), who was actually the first to recognize the systematic nature of the alternations involved, but only failed to see that ${ }^{*}-i$ - in compounding first members also took part in the alternations.

5 The term 'Caland system' was coined by Nussbaum (1976: 5). Rau, closely following Nussbaum, speaks of "a certain subset of IE roots that take a more or less well-defined subset of IE nominal suffixes that stand in a close derivational relationship and can be thought of as mutually implying one another" (2009: 70).

6 Cf. Meissner (2006: 18), although he does not include the comparative and superlative forms in the Caland alternations, because "the more we go back in time the more universal the use of the inherited suffix *-ios- for the comparative becomes". 
From a Greek point of view, these suffixes (as well as adverbial $-\alpha$, on which see section 5.2.9) can be called 'central', as opposed to 'marginal' suffixes (such as - $\nu o^{-}$and - $\left.\mu 0-\right) .{ }^{7}$ In addition, several verbal formations have close ties to these nominal forms. In Greek, these are notably the stative verbs in - $\varepsilon \omega$ (with a Homeric aorist in - $\eta \sigma-)$ and the factitive verbs in - $v \omega \omega$ and/or - $\alpha i v \omega$. The only Greek root to attest all nominal and verbal formations just mentioned is that of xpátos 'might'; derivations from this root will be extensively discussed in chapter 5. Most Greek 'Caland' roots, however, have one or several gaps in their 'system'.

Already before our first attestations, many Greek 'Caland' roots generalized one root vowel throughout the entire system of derivations. ${ }^{8}$ Thus, beside the adjective $\tau \alpha \chi u$ 's 'quick, swift', we find a comparative $\theta \dot{\alpha} \sigma \sigma \omega \nu$, a superlative $\tau \dot{\alpha} \chi \mid \sigma \tau \circ \varsigma$, a neuter abstract $\tau \dot{\alpha} \chi \chi \varsigma$ 'speed', and an adverb $\tau \dot{\alpha} \chi \alpha \alpha$, all of which are attested from Homer onwards. As we will see below, there are good arguments for reconstructing an original non-ablauting $e$-grade root in the forms of comparison and in the neuter abstract, at least for the variety of late PIE from which Proto-Greek developed. ${ }^{9}$ This suggests that the forms $\theta \dot{\alpha} \sigma \sigma \omega \nu, \tau \dot{\alpha} \chi\llcorner\sigma \tau \circ \varsigma$, and $\tau \dot{\alpha} \chi \chi \circ$ s were influenced in their root vocalism by the positive $\tau \alpha \chi \dot{v} \varsigma$, which can be considered the basic formation.

A second example is furnished by the following Greek forms derived from

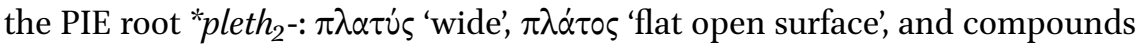
in - $\pi \lambda \alpha \tau \dot{\eta} \varsigma$. An $e$-grade root would be expected in the $s$-stem noun and adjective (cf. Ved. práthas-), ${ }^{10}$ but again, Greek has forms with $a$-vocalism. The system has clearly been reshaped on the basis of the adjective."

The terminology is that of Nussbaum (1976: 6). For the root $x v \delta$ - in question, another pos-

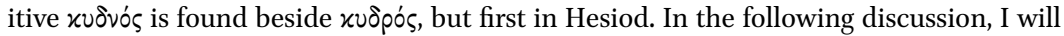
leave most 'marginal' Caland suffixes out of consideration, though some instances (such as $-\alpha \lambda \varepsilon \dot{\circ} \varsigma$ ) will treated in more detail.

8 See Meissner (2006: 71).

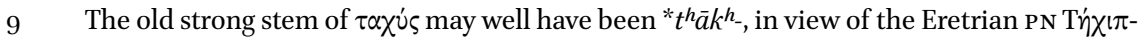

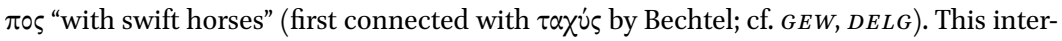

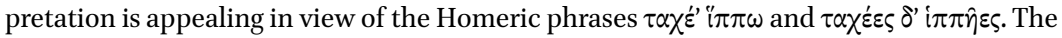
alternative etymology advocated by Lamberterie (1990: 584-590) seems less attractive to me.

10 The form $\pi \lambda \alpha \tau \alpha \mu \omega^{\prime} v$ 'flat stone or rock' (with root-final $-\alpha-<{ }^{*} h_{2}$ ) does not belong to the Caland system in Greek, but it has an immediate formal counterpart in Ved. prathimán'extension'. As a morphologically isolated and lexicalized item, $\pi \lambda \alpha \tau \alpha \mu \omega \dot{\nu}$ must be of considerable antiquity. On the basis of the comparison with Ved. prathimán-, a PIE pre-form *pleth $h_{2}$-món- has been reconstructed (cf. NIL 564). However, as Jesse Lundquist points out to me, the latter form may well be of inner-Vedic date (created as an alternative for the older abstract formation práthas-; the Vedic form is discussed by Rau 2009: 121, 133). Consequently, one might also derive $\pi \lambda \alpha \tau \alpha \mu \omega \dot{\omega} v$ from PIE * $p l t h_{2}-m o ́ n-$. 
These fairly trivial examples teach us that nominal forms with $-\rho \alpha-,-\lambda \alpha$ - or $-\alpha \rho-,-\alpha \lambda$ - need not (or do not) directly continue a pre-form with *r or * ${ }^{*}$. Thus, in order to judge the provenance of Caland forms and their pertinence as evidence for the regular reflex of ${ }^{*} r$ or ${ }^{*}$, we must first obtain a clearer picture of the expected ablaut paradigms, in PIE and in early Greek, of the formations involved. Before turning to the reconstruction of these paradigms, however, an important caveat must be made. Many Caland roots are considered to be primarily adjectival or nominal, either because verbal forms are unattested or

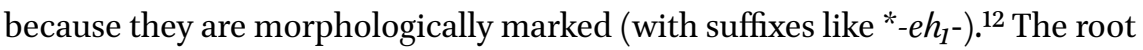
of $\tau \alpha \chi \dot{v} \varsigma$ offers an illustrative example. However, as stressed by Lamberterie (1990: 38-39), many IE languages have examples of deverbal $u$-stem adjectives; in these cases, influence of verbal forms on the root shape of the adjective (and other nominal fomations) must be reckoned with. For instance, Lith. platùs 'extended' beside iš-plečiù 'I stretch out' follows the model of e.g. badùs 'sharp' beside bedù 'I sting'. An important consequence of this observation is that forms like Lith. platùs do not allow us to reconstruct an $o$-grade root allomorph in the PIE $u$-stem adjectives. ${ }^{13}$

Within Greek, too, there is some evidence for the derivation of $u$-stem adjectives from intransitive verbs. Lamberterie (1990: 414-417 and 542-544, cf. 957) adduces the examples Hom. $\beta p i \theta$ 's 'heavy' (from Hom. $\beta p i \theta \omega, \beta \varepsilon \varepsilon p i \theta \alpha$ 'to be

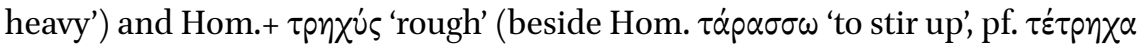
'to be in upheaval'). Risch (1974: 65), too, observed that Caland forms are

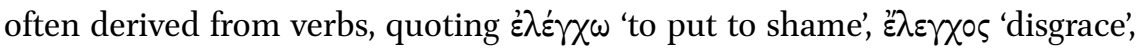

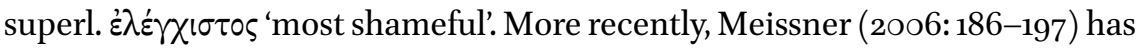
demonstrated that Greek $s$-stem adjectives are frequently derived from intransitive verbal formations like the aorist in - $\eta \nu$ and (following Tucker 1990) from stative verbs in ${ }^{*}-\bar{e}$-, and Blanc (2018) has adduced abundant evidence for ${ }^{-} \eta \varsigma$ as a general deverbal compound suffix. ${ }^{14}$

It was thought for a long time that such deverbal Caland formations were innovations of Greek. However, Rau shows that a deverbal origin can also be assumed for a large number of Caland adjectives in Indo-Iranian, where "the

$\ddot{\alpha} \pi \lambda \varepsilon \tau \circ \varsigma^{\prime}$ 'immense', which he derives from *sm-pleth ${ }_{2}$-eto-, a doublet of *sm-pleth ${ }_{2}$-es- as reflected in Ved. sáprathas- 'extended'.

Balles, who is followed in this by Rau (2009) and various other scholars, has introduced into Indo-European Linguistics the descriptive framework developed by Dixon (1982). According to this view, most Caland adjectives belong to the class of 'property concept adjectives', i.e. they "predicate some non-verbal and non-relational property concept state" (Rau 2009: 78). Typical examples are adjectives for dimensions, physical properties, and speed.

13 As was done by Kuiper (1942: 55), who compared neuter nouns of the type *dór-u, *dr-éu-s.

14 For the deverbal nature of adjectives in -pós, see now Van Beek 2o21a. 
vast majority of Caland system adjectives (...) pair with stative/inchoative and factitive formations that are to all appearances primary" (2009: 138-139). Frequently, the primary verb is a full-grade thematic formation, mostly an intransitive middle, sometimes accompanied by a secondary causative active form. In the example used earlier, PIE * ${ }^{*} l e t h_{2}$-, Vedic has an intransitive primary verb práthate 'spreads'. In Greek, too, many individual Caland systems stand beside primary thematic middle presents (see the overview in Rau 2009: 152-

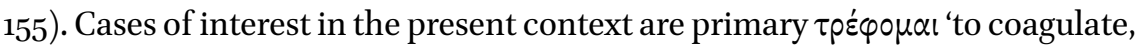

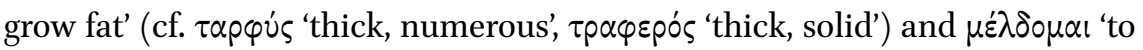
become soft' (cf. $\beta \lambda \alpha \delta \delta$ ' $\varsigma^{*}$ 'weak'). ${ }^{15}$ Clearly, such cases are archaisms: it was no longer possible to derive an adjective in -v́ within Greek.

After these preliminary remarks, let us consider in more detail the ablaut paradigm of the most important primary formations: $u$-stem adjectives, forms of comparison, and $s$-stem nouns and adjectives.

\subsubsection{The u-stem Adjectives}

In Greek $u$-stem adjectives we generally find a zero-grade root and suffixal ablaut. For instance, the suffix of $\beta \alpha$ pús 'heavy' is - $v$ - in the nom.-acc. sg. of the masculine and neuter, and reflects *-eu- elsewhere in the paradigm. A similar situation is reflected in cognate Indo-Iranian adjectives of the type urú- 'wide', prthú- 'broad', in which the suffix of the $\mathrm{m}$. and $\mathrm{n}$. oblique stem derives from *-eu-. Since this type of suffix ablaut is at home in the proterodynamic (PD) accent/ablaut-paradigm, the reconstruction of a regular PD $u$-stem adjectival paradigm for PIE (including root ablaut, i.e. strong stem *CéRC-u-, weak stem ${ }^{*} C R C$-éu-) is widely accepted. ${ }^{16}$

Since this ablaut pattern could play an important role in accounting for

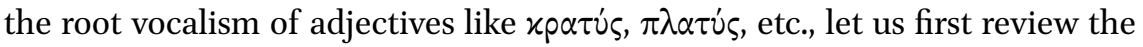
reasons for reconstructing it. Within Greek, an important piece of evidence is $\delta \alpha \sigma u$ ' 'hairy; densely grown'. The main question here is how to explain the retention of intervocalic $-\sigma-$; this has previously been ascribed to expressive gemination (Szemerényi 1954: 261) or to a "double treatment" of *-NsV- (DELG s.v. $\delta \alpha u \lambda$ ó $_{\text {) }}$, but neither of these proposals offers a satisfactory solution. ${ }^{17}$ The formation is clearly inherited, because a stem ${ }^{*} d n s-u$ - is also presupposed by

15 See sections 4.3 and 4.4 on these words.

16 See e.g. Fischer (1991), Rix (1992: 123 and 147), Meissner (2006: 35), Beekes (2011: 221). However, the acceptance is not universal: a different view is expressed by Lamberterie (1990, e.g. 953), who argues that instances of a full grade root in $u$-stem adjectives were introduced from coexisting verbal forms.

17 Szemerényi accepts Meillet's view "that $-\sigma-$, earlier $-\sigma \sigma-$, is due to expressivity", while deriving $\delta \alpha u \lambda o ́ \varsigma$ from *dnsulo-. This view is accepted by Lamberterie (1990: 702). 
the near-synonym $\delta \alpha \nu \lambda o ́ s$ (or perhaps rather $\delta \alpha \hat{\lambda} \lambda$ os) 'dense, hairy, shaggy' < *dns-u-ló-. ${ }^{18}$ In Latin we find dènsus 'thick, dense', and Hittite has daššu- 'strong, powerful; heavy, well-fed; difficult, important' (among other meanings). The latter form is important because its geminate -šš- can only be explained if we reconstruct *déns-u- rather than *dns-u- (EDHIL, s.v. daššu-). Like the verbal forms $\delta \alpha \hat{\nu} v a l$ 'to learn', $\delta \varepsilon \delta \alpha \varepsilon$ 'taught', and the relic first compound member of

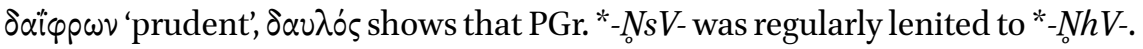
This makes the retention of $-\sigma$ - in $\delta \alpha \sigma \dot{s} \varsigma$ an even more urgent problem.

The retention can be explained, however, if we suppose that $\delta \alpha \sigma \dot{\varsigma} \varsigma$ continues an ablauting paradigm *déns- $u$-, * $d n s s-e ́ u-,{ }^{19}$ and that intervocalic *-s- was lenited earlier than intervocalic *-Ns-. In this case, * ${ }^{*} n h$-eu- could be restored to *dns-eu- on the basis of the strong stem *dens-u-. In $\delta \alpha \nu \lambda$ ó $^{*}$, on the other hand, the -s- was not restored, presumably because the paradigm did not have ablaut. Thus, the pair $\delta \alpha \sigma u ́ \varsigma$ beside $\delta \alpha u \lambda o ́ s$ provides indirect evidence that $u$ stem adjectives preserved paradigmatic root ablaut in Proto-Greek; in addition, the presence of an $e$-grade in the PIE paradigm is proven by Hittite daššu-.

There is some further suggestive Greek evidence for the presence of forms with an $e$-grade root within the original paradigm. Willi (2002) attractively

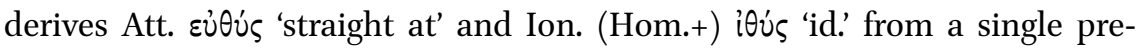
form PGr. ${ }^{*}$ ieut ${ }^{h} u-{ }^{20} \mathrm{He}$ compares this Proto-Greek form with Lith. judùs belligerent'21 and derives both from the verbal root ${ }^{*}(H)$ ieud $^{h}$ - 'to go straight at', reflected in Ved. $y u d h$ 'to fight', Lat. iubeō 'to order' (OLat. ioubeō 'to sanction'), Lith. jùsti 'to get moving', judéti 'to be agile, stir (intr.).'22 Since this verbal root is unattested in Greek, it is likely that forms with $e$-grade root were originally present in the paradigm, i.e. PIE * $(H) i e ́ u d^{h}-u$-, ${ }^{*}(H) i n u d^{h}$-éu-.

As for PIE * sueh ${ }_{2} d-u$ - 'agreeable, tasty', all IE languages that continue this formation agree in showing the reflex of a full grade root: Gr. ìoús, Ved. svādú-, Lat. suāvis, OE swōt, etc. Since zero grade forms of this root are found in Vedic (caus. sūdáyati 'to make acceptable', súda- 'sweetness'), we know that it could undergo

18 On $\delta \alpha u \lambda o ́ \varsigma$ vs. $\delta \alpha \hat{\lambda} \lambda \circ \varsigma$, see Radt $(1982 ; 1994)$, who argues that the barytone accentuation is old; but according to Probert (2006: 368) "the case is by no means clear-cut". For the reconstruction, see Lamberterie (1990: 702), GEW and $D E L G$ (both s.v. $\delta \alpha \nu \lambda o ́ s)$.

19 For this idea, see also Nikolaev (2010: 238-239, 241, with references to earlier literature).

20 With dissimilation to ${ }^{*} e i t^{h} u$ - in Ionic, the intermediary stage ${ }^{*} e i t^{h} u$-being attested in the derivative $\varepsilon(\theta \nu[\nu \eta] \nu$ 'fine' (Chios, 5 th c.); see Willi (2002: 129).

21 The correctness of this identification with Lith. judùs is suggested by Homeric phraseology: i $\theta \dot{\jmath} \varsigma \alpha \dot{\alpha} \chi \varepsilon \sigma \theta \alpha$ l means 'to fight face to face'.

22 Willi, however, explains the full grade of PGr. "ieut ${ }^{h} u$ - by assuming that it replaced the (in his view expected) outcome *i่vis < * $(H) i n d^{h} u^{\prime}$ - on euphonic grounds. This seems an emergency solution to me. 
ablaut in the proto-language. ${ }^{23}$ The question remains whether one can exclude that the lexical entry * $\operatorname{sueh}_{2} d-u$-had a non-ablauting root already in the particular chronological phase that corresponds to reconstructed PIE. In my view, the most natural scenario would be to reconstruct a PD paradigm for PIE itself, with subsequent generalization of the full grade root in the daughter languages. Indeed, there would have been a clear motive for this generalization. After the loss of laryngeals, the outcome of the zero grade * $s u h_{2} d$ - was * süd-in most languages; and since the resulting ablaut *sūa $d-$ : *süd-was anomalous, it would not be surprising if all daughter languages eliminated it independently. ${ }^{24}$ One also wonders whether the vocalism of $\dot{\eta} \delta \dot{s} \varsigma$ was perhaps influenced by the primary thematic verb underlying ท̈ঠo date 'to become tasty'). This explanation is conceivable for Greek, but it is less evident for most other branches that have a trace of * ${ }^{*} u e h_{2} d-u$-, as they show no trace of the primary verb. We must therefore assume that the PIE adjective contained an $e$-grade root at least in the strong case forms.

In various different daughter languages, there are scattered remains of original $u$-stem adjectives with an $e$-grade root. Examples:

- Lat. brevis 'short' < *mreg'hui-<< *mrégh-u-;25

- Lat. gravis 'heavy; important' $<{ }^{*} g^{w}$ rau- plus $-i-<<{ }^{*} g^{w} r e h_{2}-u-; 26$

- Arm. metk 'soft' < *meldui- << *meld-u- 'weak; soft'; 27

- Hitt. tê̄pu- 'little, few' $<{ }^{*} d^{h} e ́ b^{h}-u-.^{28}$

23 The Vedic forms with guna root (pres. svádati, caus. svadáyati) can be explained by Lubotsky's Law (Lubotsky 1981).

24 It is even possible that a trace of * $s u h_{2} d-u$ - is found in Goth. sutis 'quiet, peaceful', but there are various problems with this idea: see Lamberterie (1990: 487-489) with further literature.

25 See Fischer 1982 and 1991. I do not consider it likely that the root vocalism of brevis was taken over from the comparative brevior (Sihler 1995: 358); one expects the base form (adjective) to influence the derivative (comparative). This is in fact precisely what happened in Latin, because comparatives like brevior contain the * $u$ - of the positive.

26 For this reconstruction of Lat. gravis, see Fischer (1982), Nussbaum (1976: 41, 68). Greek ßapús, Ved. gurú-, Av. gouru-, Goth. kaurus (etc.) all point to a zero grade root " ${ }^{*}{ }^{w} r H-u-$.

27 For this reconstruction and for different possibilities, see $N I L 483-484$. A zero grade root is found in Ved. mrdú- 'soft, weak', Gr. $\beta \lambda \alpha \delta \varepsilon i \varsigma$ (see section 4.4) and other cognates. The reconstruction of Lat. mollis 'weak; soft' is debated. Nussbaum (1976:67) claims that *mlduiwould turn up as Latin *molluis, and concludes from this that the pre-form of mollis must have been * $m l d-i$ - I fail to see, however, how the alternative reconstruction *meldu- plus $-i$ - can be excluded: in *meldui-, with a larger consonant cluster, the $d$ may well have been lost before the development of intervocalic -du- to -u- (as in suāvis) took place. In that case, the development was *meldui- > "melui- > *melli- > *molli-. Thus, Lat. mollis possibly represents an old $e$-grade, too.

28 See Kloekhorst 2014: 184 on the distribution between plene and non-plene spellings in tepu-. 


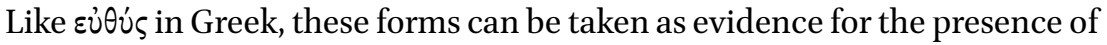
an $e$-grade root somewhere in the original $u$-stem paradigm. It must be granted, however, that the evidence is indirect. As for Lat. brevis and gravis, the exact derivational history of this type of Latin $i$-stems is disputed, ${ }^{29}$ but in my view it cannot be doubted that the type ultimately developed from PIE $u$-stem adjectives, as there are too many precise lexical correspondences between Latin and the other languages. Thus, the Latin forms can be taken as evidence for proterodynamic ablaut (with Fischer 1991: 7).

In sum, the case of $\delta \alpha \sigma u ́ \varsigma$ (and $\delta \alpha \nu \lambda \dot{\varsigma}$ ) beside Hitt. daššu- suggests that $u$ stem adjectives had PD inflection with root ablaut in PIE. Additional corrobora-

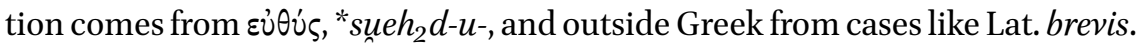
If the explanation proposed here for the retained sibilant in $\delta \alpha \sigma u$ s is correct, it proves that the root ablaut was retained up till Proto-Greek.

In Van Beek 2013, I went one step further, assuming that the root ablaut was retained as late as Proto-Ionic. I used this to argue for an analogical origin of the reflex - $\rho \alpha$ - in Greek adjectives like $\beta p \alpha \chi ن$ u. When the weak stem * $m r k^{h} e_{n} u$-vocalized as *markhéu-, it would have been analogically changed into *mrak ${ }^{h} e^{\prime} u-$ under influence of the strong stem * $m r^{\prime} k^{h} u$-, after which it would have ousted the latter. This assumption is rather costly, however, and in section 4.3.3 I will propose to account for the leveled zero-grade reflex in an alternative way, by means of influence of the forms of comparison.

\subsubsection{Primary Comparatives and Superlatives}

The reconstruction of the so-called primary comparatives and superlatives is important for our purposes for more than one reason: the formations are unproductive in Greek, and their root vocalism shows traces of ablaut with respect to the positive. As we will see, a fair amount of analogical reshaping must have taken place in these formations at a relatively shallow time-depth.

According to the most widespread view, ${ }^{30}$ PIE primary comparatives had an $e$-grade root with ablaut in the suffix, whereas primary superlatives regularly had a zero grade root. This is motivated as follows by Schwyzer (1939: 538):

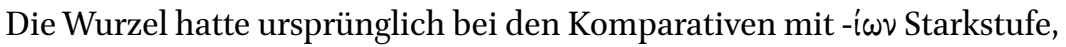

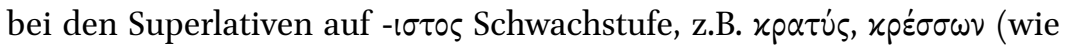

29 Nussbaum (1976: 67-68) explained Lat. -vi- as a complex suffix consisting of the 'central' suffixes $-u$ - and $-i$. In more recent times, however, he has revoked this idea (cf. Weiss 2oog: $315)$.

3o It is found, for instance, in Meier-Brügger (1992a: 84, less explicitly 2010: 357-358), Rix (1992: 168), Chantraine (1961: 109-110). 


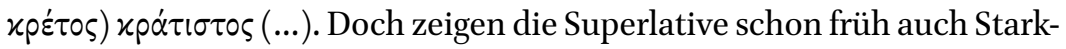

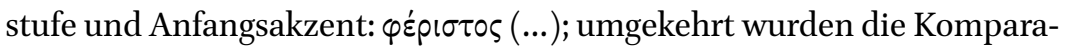
tive früh dem Superlativ bzw. Positiv angeglichen, z.B. dor. xápp $\omega v$ kret.

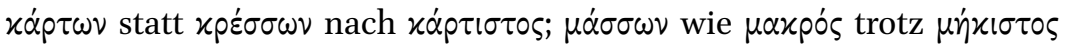
$\mu \hat{n} x \circ \varsigma_{(\ldots)}$

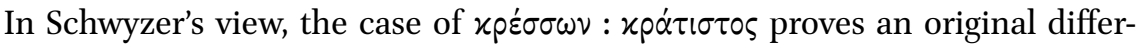
ence in root vocalism between the PIE comparative and superlative. In order to maintain this, it must be assumed that some superlatives acquired the $e$ grade root of the comparative at an early date. ${ }^{31}$ To this, one may object that the reconstruction of a zero grade root in the superlative is based mainly on

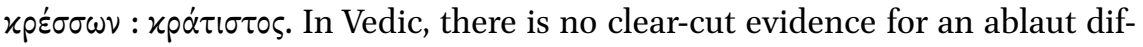
ference between comparative and superlative: both formations regularly have

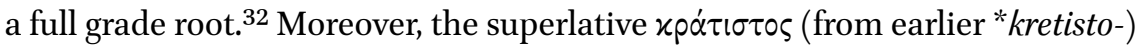

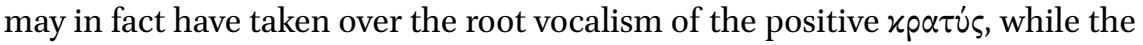

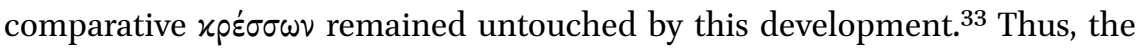
only direct piece of evidence for the alleged difference in root ablaut between the PIE comparative and superlative falls away.

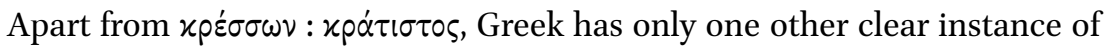
an ablaut difference between primary comparative and superlative: $\mu$ 'ं 'longest' beside $\mu \alpha x p o ́ s$, comp. $\mu \dot{\alpha} \sigma \sigma \omega \nu .^{34}$ The root vocalism of $\mu \dot{\alpha} \sigma \sigma \omega \nu$ may well have been influenced by the positive $\mu a x p o ́ s$, replacing an older *mākios- or

$31 \quad$ See Ruijgh (1992: 91 n. 50), who speculates that this leveling of ablaut grades could start when instances like comp. * $h_{2}$ er-ios- : superl. ${ }^{*} h_{2} r$-is-tHo-developed to PGr. *arios-, *aristoby regular sound change.

32 A review of the problem and the history of early research on it can be found in Seiler (1950: 21-22), who does not reach a definite conclusion. The idea that the PIE superlative had a zero grade root comes from Osthoff (1910), who drew attention to the oxytone accentuation of some Vedic superlatives (e.g. kanișthá- 'youngest', davișthám 'far away'). Such forms are probably archaic: in Classical Sanskrit, they are lost or replaced by rootaccented forms. However, the final accent of these superlatives is not necessarily related to their root vocalism: even if the suffix was accented (PIE -tHó-), the root may have had a full grade, because the PIE superlative $\left({ }^{*} \mathrm{CeC}\right.$-is- $t \mathrm{Ho}$ - or $\left.{ }^{*}-\mathrm{mHo}-\right)$ was in all probability derived from the weak stem of the comparative. The latter can be reconstructed as ${ }^{*} \mathrm{Ce}$ is- on account of forms like Goth. mais 'more' < " $\mathrm{meh}_{2}$-is-.

33 See chapter 5 for further discussion of these forms.

34 The Attic pairing of a comparative $\partial \lambda \varepsilon i \zeta \omega \nu$ beside a superlative $\partial \lambda i \gamma(\sigma \tau \circ \varsigma$ also looks archaic at first sight. However, given that Homer has $\partial \lambda i \zeta \omega \nu$, Attic $\partial \lambda \varepsilon i \zeta \omega \nu$ is rather to be analyzed as secondarily influenced by its counterpart $\mu \varepsilon i \zeta \omega \nu$ (which itself replaces older $\mu \dot{\varepsilon} \zeta \omega \nu$ ). This analysis is confirmed by the fact that Att. $\partial \lambda \varepsilon i \zeta \omega v$, like $\mu \varepsilon i \zeta \omega v$, has a spurious diphthong (see Seiler 1950: 101-103). 
*mākios- (or its outcome). ${ }^{35}$ The superlative $\mu \eta \dot{x}$ « $\tau \tau \circ \varsigma$, on the other hand, is suggestive evidence for an original $e$-grade root in this formation. ${ }^{36}$

It is much more attractive, then, to reconstruct an $e$-grade root for both the comparative and the superlative paradigm. This not only directly explains the Vedic forms, but also accounts for isolated Greek cases like $x \varepsilon p \delta i \omega \nu$ 'more

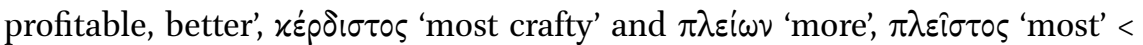
"pléh ${ }_{1}$ ios-, " $p l e ́ h_{1}$-ist $(H) o$ - (beside $\pi 0 \lambda u ́ \varsigma$ 'many, much'). These $e$-grade formations were preserved because they were not (or could not be) influenced by a

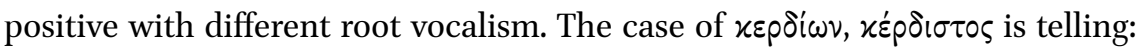
the older zero-grade root is preserved only in the non-Ionic-Attic form xop-

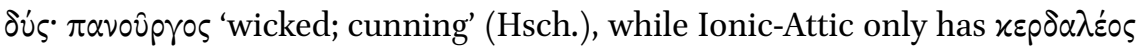
'wily; profitable' (Hom.+), with a secondary Caland suffix and an $e$-grade that was probably taken from $x$ źpঠos. These examples corroborate the idea that zero grade root vocalism normally spread from the positive to the forms of compar-

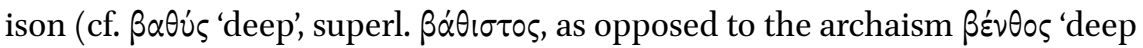
place').

A remaining issue concerns the possibility that the PIE comparative had paradigmatic root ablaut. This paradigm is often reconstructed with an accented, non-ablauting $e$-grade root, and its weak stem is supposed to underlie the superlative formation. ${ }^{37}$ This matches the situation in Indo-Iranian, e.g. Ved. ugrá- 'strong', comp. ójiyas-, superl. ójiștha-, or yúvan- 'young', superl. yáviștha-. Root accentuation in the comparative is also required for a pre-stage of Germanic, as indicated by the preserved reflexes of Verner's Law in Goth. juggs 'young' comp. juhiza, from PGmc. *jungá-, *júnh-iz-.

As for suffixal ablaut, it is common to reconstruct the oldest paradigm as having qualitative ablaut: *CéC-ios- versus $C(e) C$-iés- (and, in Beekes' view, also ${ }^{*} C(e) C$-is-). Indeed, an $e$-grade suffix somewhere in the paradigm would help to

35 The long root vowel of the neuter and adverb $\mu \hat{\alpha} \sigma \sigma o v$ does not derive from * mākiōn, but is secondary; cf. Barber (2013: 169-170).

36 Seiler (1950: 75-76, following Brugmann) thought that $\mu$ '่ neuter $s$-stem $\mu$ ทेxos, but this assumption is both unmotivated and unnecessary. My main

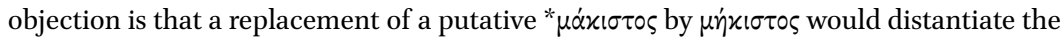
superlative from comparative $\mu \dot{\alpha} \sigma \sigma \omega \nu$ and positive $\mu \alpha x$ pós (i.e. this analogy would lack all motivation). Besides, it would entail a change in prosodic structure, a problem which does not exist if we assume a replacement of *mākiōn by *makiōn. It is quite possible that the

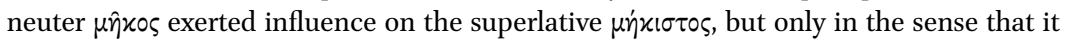
helped to preserve it against the pressure of $\mu \alpha x p \operatorname{s} \varsigma, \mu \dot{\alpha} \sigma \sigma \omega \nu$.

37 So strong stem *CéC-ios- vs. weak stem *CéC-is-in the comparative, and *CéC-is-t(H)o-for the Greek and Indo-Iranian superlative: see Seiler (1950: 21: "Niemand bestreitet dies", with reference to Meillet and Brugmann); Sihler (1995: 358); Weiss (2009: 356). 
explain Lithuanian comparatives of the type gerèsnis 'better' (to gẽras 'good'). ${ }^{38}$ Another argument is Lat. maiestās 'power', which seems based on a Proto-Italic comparative stem * mag-ies-. Finally, the Skt. comparative suffix -iyas- does not show the effects of Brugmann's Law and may therefore have to be traced back to *-ies- as well. ${ }^{39}$ Still, whatever the exact reconstruction of the PIE paradigm, the Greek comparatives are understood best from a (post-PIE) paradigm nom. ${ }^{*} C e ́ C-i \bar{c} s$, acc. ${ }^{*} C e ́ C$-ios- $m$, gen. ${ }^{*} C e ́ C-i s-o s,{ }^{40}$ because only in this way do the distributions discussed above receive an account. ${ }^{41}$

In conclusion, the vocalism of Greek primary comparative and superlative formations is explained most economically on the assumption that both had a non-ablauting $e$-grade root in (early) Proto-Greek. In most adjectives, the zero grade reflex of the positive subsequently ousted this $e$-grade, which was retained only in a number of relic forms.

\subsubsection{The s-stem Nouns and Adjectives}

As is well known, Schindler (1975) argued that neuter $s$-stem nouns originally had proterodynamic inflection in pre-PIE, i.e. a strong stem ${ }^{*} C e ́ C$-s beside a weak stem ${ }^{*} C C$-és-. He also sketched a way to derive the standard paradigm to be reconstructed for PIE (nom. *CéC-os, gen. *CéC-es-os) from this earlier paradigm. In the late proto-language, the full grade root would have been generalized in most individual $s$-stem neuters, and the root accent was also generalized. Following this reasoning, Stüber (2002: 19) concluded that "für die Grundsprache ein intakter Wurzelablaut angenommen werden muss". Her main addi-

38 Slavic has -bs- (continuing zero grade ${ }^{*}-i s-$ ) and Old Prussian has forms deriving from * ${ }^{*} i s-$, too (cf. Stang 1966: 267-268).

39 See Barber (2013: 157).

40 That is, a paradigm with non-ablauting $e$-grade root and $o$ /zero suffix ablaut. In Greek, the suffix allomorph *-is- was subsequently eliminated in favor of *-ios-, a process paralleled in other 3 rd declension paradigms.

41 In other words, the appearance of $e$-grades and zero grades in Greek forms of comparison is not at all random. I therefore do not share Barber's pessimism (2013: 157-158) regarding the possibility to draw conclusions about the original root ablaut of specific comparative

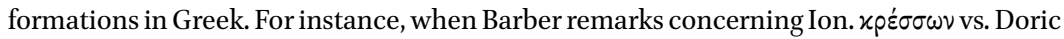

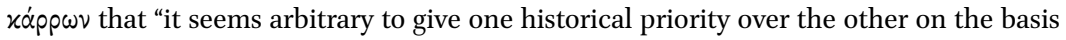
of ablaut grade alone, if there is a good chance that there was some sort of root ablaut alternation in the first instance" (2013: 158), he fails to note that the vocalism of $x p \varepsilon \dot{\sigma \sigma \omega \nu}$ is aberrant within the adjectival paradigm (and is therefore an archaism), whereas that of xápp $\omega \nu$ can be easily explained by analogical leveling (see chapter 5 for further details). In other words, while it is theoretically possible to explain $x \rho \varepsilon ́ \sigma \sigma \omega \nu$ beside $x \dot{\alpha} \rho \rho \omega \nu$ as reflecting original root ablaut in the comparative paradigm, it is much less costly to explain this difference from a paradigm without root ablaut. 
tional arguments for this claim are inherited $s$-stems with a zero-grade root that are attested in more than one daughter language (e.g. piros 'shiver' beside Lat. frigus 'cold'), and the word for 'mouth' in Hittite.

Within Greek, however, there is no direct proof of root ablaut in the neuter $s$-stems. Important observations on this issue have been made by Meissner (2006). For instance, it has been argued since Brugmann (for references see Meissner 2006: 72) that the coexistence of $s$-stem neuters like $\pi \dot{\alpha} \theta$ os 'experience' and $\pi \varepsilon \dot{\varepsilon} v \theta_{0}$ ' 'suffering, grief' must reflect a PIE paradigm with root ablaut. ${ }^{42}$ However, Meissner convincingly shows (2006: 65-68) how post-Homeric $\beta \dot{\alpha} \theta 05$ 'depth' replaces Homeric $\beta \varepsilon ́ v \theta 0 \varsigma$, and how $\pi \dot{\alpha} \theta 0 \varsigma$ starts to appear at the side of the relic form $\pi \dot{\varepsilon} v \theta \circ \varsigma$. His chronological observations are strengthened by his semantic analysis of the forms: $\pi \dot{\alpha} \theta \circ \varsigma$, derived from the aorist $\pi \alpha \theta \varepsilon i v$ (aided by $s$-stem adjectives like Hom. aivo $\alpha \theta \dot{\eta} s^{\prime}$ 'who has experienced terrible things'), has the same broad range of meanings as the verb, whereas $\pi \dot{\varepsilon} v \theta$ os only means 'suffering'; and $\beta \dot{\alpha} \theta$ os functions as a deadjectival abstract to $\beta \alpha \theta$ ús, whereas $\beta \varepsilon \dot{v}$ $\theta \circ \varsigma$ is a noun with concrete referents. Since $\pi \dot{\alpha} \theta 0 \varsigma$ and $\beta \dot{\alpha} \theta 0 \varsigma$ are secondary creations, $\pi \dot{\varepsilon} v \theta 0 \varsigma$ and $\beta \dot{v} v \theta 0 \varsigma$ may simply reflect a Proto-Greek paradigm with a non-ablauting root.

In similar cases, it must be borne in mind that neuter $s$-stems could be synchronically derived from verbal roots throughout Greek prehistory. For instance, Stüber (2002: 199-200) discusses the etymology that derives xîठos 'worry; thing to take care of' (Hom.+) with Goth. hatis 'hate' and Welsh cawdd 'rage, grief' from an inherited root-ablauting neuter ${ }^{*} k e ́ h_{2} d$-os, ${ }^{*} k h_{2} d$-és-. This analysis is unfounded because the Greek form can be derived from the verb

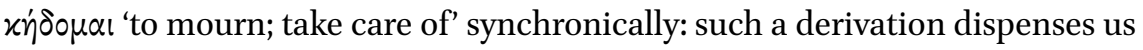
from the task of accounting for the semantic and morphological divergence between $x \hat{\jmath} \delta \circ \varsigma$ and the alleged cognate formations. A similar explanation can be given for the zero grade root in piros, which stands beside an intransitive

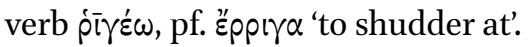

Stüber (2002: 199-200) discusses the case of $x \hat{\eta} \delta 0 \varsigma$ together with two other examples: Indo-Iranian *uárH-as- 'width' beside *úrH-as- 'breast', and the word for 'mouth' (Hitt. aiš, gen. sg. iššaš, Ved. ins. sg. āsáa, Lat. ōs, OIr. á). But: “Damit ist allerdings die Zahl derjenigen neutralen $s$-Stämme, für die Wurzelablaut gesichert ist, auch schon erschöpft". ${ }^{43}$ Moreover, even if *úrH-as- 'breast' evi-

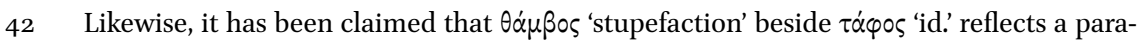
digm containing the root shapes ${ }^{*} d^{h} e m b^{h_{\text {- }}}$ and ${ }^{*} d^{h} m b^{h}$-: cf. Hackstein 2002: 237. On this problematic word, see below.

43 Beside the inherited $s$-stem vé $\varphi$ os 'cloud' (cf. OCS nebo, Hitt. nēpiš, Ved. nábhas-), forms like Ved. ámbhas 'water', Arm. amb 'cloud' have been interpreted as containing the out- 
dently has a claim to antiquity, it would be difficult to exclude that the form ${ }^{*} H u a ́ r H-a s$ - arose beside the adj. *HurH-ú- as a productive adjectival abstract within Proto-Indo-Iranian. Finally, the reconstruction of the Anatolian word for 'mouth' is beset with difficulties (see EDHIL s.v. aiš). It is therefore likely that PIE (that is, nuclear PIE at least) had already eliminated most, if not all traces of root ablaut in the $s$-stem neuters.

In PIE, possessive $s$-stem compounds could be regularly derived from $s$ stem neuters. Well-known examples such as $\varepsilon \dot{u}-\mu \varepsilon v \eta \dot{\zeta}, \delta \nu \sigma-\mu \varepsilon v \eta \dot{\varsigma} \sim \mu \varepsilon \dot{\varepsilon} v \varsigma$, beside Ved. su-mánas-, dur-mánas- mánas show that this procedure was inherited. Another example from Greek is $\pi 0 \lambda v-\pi \varepsilon v \theta \dot{\eta} \varsigma$ beside $\pi \varepsilon v \theta 0 \varsigma$ 'suffering' (both Hom.). The comparative evidence suggests that the $s$-stem compound had a non-ablauting $e$-grade root, just like the simplex. But there are also compounds with a zero grade root, e.g. Hom. aivo $\alpha \Theta \theta^{\prime} \varsigma$ 'who has suffered terrible things'. As Tucker (1990), Meissner (2006) and recently Blanc (2018) have shown in detail, the derivation of $s$-stem compounds from intransitive verbs was productive in Greek. In such derivations, the second compound member naturally took the vocalism of the synchronic verbal stem: thus, $\alpha i v o \pi \alpha \theta n$ ' sas derived from the aor. $\pi \alpha \theta \varepsilon i \nu$ 'to experience.' This is also the origin of forms with zero grade vocalism in the simplex: $\pi \dot{\alpha} \theta 0 \varsigma$ originated as a backformation from compounds like $\alpha i v 0 \pi \alpha \theta \dot{n}$ (Meissner 2006: 88). There is no reason, then, to reconstruct root ablaut for PIE $s$-stem adjectives either.

\subsection{Analogical Reshaping and Re-derivation}

Having reviewed the ablaut schemes to be reconstructed for the relevant formations, we may now embark on a more detailed discussion of forms that have a bearing on the development of the syllabic liquids. The main issue to be resolved in the remaining part of this chapter concerns the outcome of ${ }^{*} r$ in the $u$-stem adjectives (sections 4.3 to 4.5). But first, I will illustrate in more detail how $a$-vocalism of the root spread from these adjectives through entire derivational systems (section 4.2.1), discuss examples of the general tendency of Homeric Greek to avoid $u$-stem adjectives and replace them with new formations (section 4.2.2), and comment on the origin of factitive verbs of the type

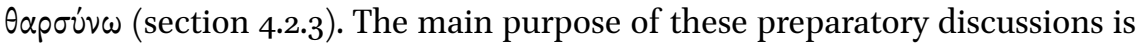

come of a zero grade root ${ }^{*} n b^{h}$ - with a re-introduced nasal. However, since an ablauting

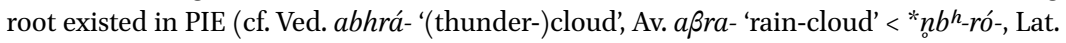
imber 'rain (shower)' $\left.<{ }^{*} n b^{h}-r i-\right)$, it cannot be proven that the $s$-stem paradigm originally harbored a zero-grade root allomorph. 
TABLE 3 Replacement of $e$-grade 'Caland' forms in Ionic-Attic

Original $e$-grade

xpé̃os (Alc.)

-xpétrns in names (Aeol., Arc.-Cypr.)

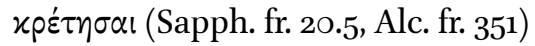

$\theta$ époos (Alc. fr. 206.2)

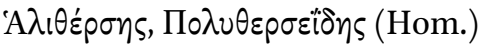

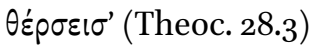

\section{Replaced with $a$-vocalism}

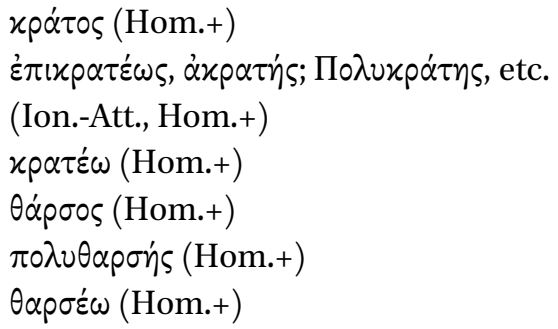

to show that many apparent zero grade forms cannot be used to determine the regular outcome of liquid vocalization. Furthermore, it appears that alternations between - $\alpha \rho$ - and - $\rho \alpha$ - in formations derived from the same root are never random reshufflings: usually a precise model can be indicated for newly formed derivatives.

\subsubsection{The Spread of a-vocalism across 'Caland' System Formations}

As we have already seen, not every form with - $\alpha \rho$ - or - $\rho \alpha$ - can be used as evidence for the outcome of ${ }^{*} r$, because many of them contain a generalized $a$ vowel. The question to be answered in this section is how exactly the $a$-vocalism started to proliferate in Ionic-Attic. Two important examples are Aeolic xpé-

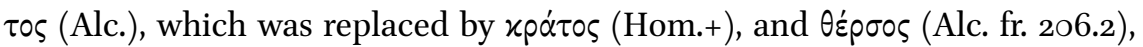
which was replaced by $\theta \dot{\alpha} p \sigma o \varsigma$ (Hom.+). The same replacement took place in the derivationally connected $s$-stem compounds and 'stative' verbs in - $\varepsilon$ ' $\omega$ (Tucker 1990: 54). See Table 3 .

It is generally agreed that the root vocalism of $s$-stem neuters was influenced by that of $u$-stem adjectives. Meissner's comment on this replacement deserves to be quoted in its entirety (Meissner 2006: 71):

... of all words with full grade, only $\pi \dot{\varepsilon} v \theta 0 \varsigma$ really remains in use while

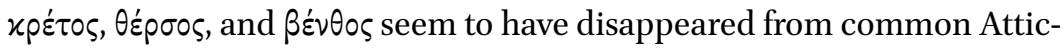
Ionic usage at a very early stage, being replaced by the zero grade forms. The first consequence of this secondary emergence of the zero grade forms is that these cannot be considered reflexes of an old paradigmatic ablaut variation in the root. The motivation for this replacement is not

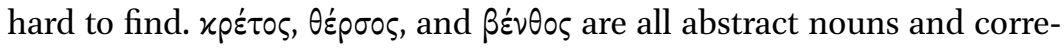
spond to the $u$-stem adjectives $x p \alpha \tau u ́ s, \theta p \alpha \sigma u ́ s$, and $\beta \alpha \theta \dot{s} \varsigma$ that have gener- 
alized (in the positive) the zero grade. These adjectives can be conceived as the more 'basic' form and it is easy to accept Risch's suggestion that the full grade was eliminated in favour of the zero grade under the pressure of the adjectives. In fact, what we see happening here is only the final stage of this regularization for in a number of cases this change was already complete at the time of our earliest attestations (cf. among others $\pi \alpha \chi \chi^{\prime} \varsigma$ : $\pi \dot{\alpha} \chi 0 \varsigma, \tau \alpha \chi \dot{v} \varsigma$ : $\tau \dot{\alpha} \chi \chi \varsigma \varsigma)$. Moreover, the trend is [almost] universally towards the vocalism of the adjective.

Not only may the adjectives be considered as more basic than neuter abstract nouns; it is difficult to indicate another source of the $a$-vocalism in the relevant $s$-stem neuters. ${ }^{44}$ Meissner makes the important observation that $\pi \varepsilon \dot{\varepsilon} \theta 0 \varsigma$ could be preserved in Homer (and even later) because it was not accompanied by an adjective. As we have seen above, it was eventually replaced by $\pi \dot{\alpha} \theta \circ \varsigma$, but this may have happened as late as the tragedians, perhaps as a backformation to compounds in - $\pi \alpha \theta \dot{\eta} \varsigma$. Another crucial example is $x \varepsilon p \delta \alpha \lambda \varepsilon$ '́s 'wily;

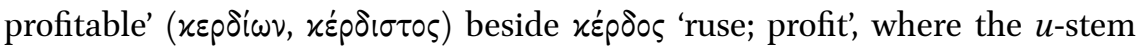

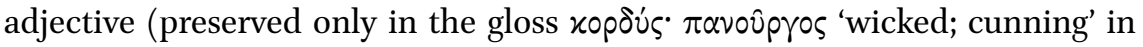
Hsch.) was apparently eliminated so early from Proto-Ionic that it could not influence the root vocalism of the other forms.

In my view, the zero grade reflex of the $u$-stem adjective first spread to other adjectival forms (the forms of comparison), and later to the noun. The pair

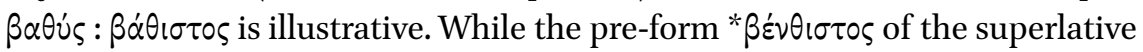
has apparently been replaced already in Homer, the neuter $\beta \varepsilon$ v́vos was preserved. Although this may be due to its occurrence in formulaic material (e.g. $\beta \varepsilon \dot{\varepsilon} \theta \varepsilon \sigma \mathrm{l} \lambda \lambda_{i}^{\prime} \mu \nu \eta \mathrm{s}$, see Meissner 2006: 65-66), the absence of $\beta \dot{\alpha} \theta 0$ (first encountered after Homer) is noteworthy. When the vocalism of $s$-stem neuters like xpátos had been levelled, the same replacement took place in derived $s$-stem

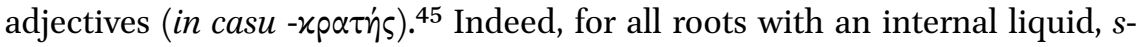
stem compounds are attested whenever an $s$-stem abstract is affected by the replacement: $-\pi \lambda \alpha \tau \eta^{\prime} \varsigma,-\varkappa \rho \alpha \tau \eta^{\prime} s,-\theta \alpha \rho \sigma \eta^{\prime} s$, and $-\tau \alpha \rho \beta \dot{\eta} \zeta$.

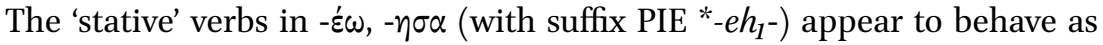
primary (underived) formations. They differ from denominative verbs derived from neuters in $-0 \varsigma$, in that the latter have a different type of aorist in $-\varepsilon \sigma(\sigma) \alpha$

44 The adverb in $-\alpha$ may have played a role in the case of $\mu \dot{\alpha} \lambda \alpha: \mu \hat{\alpha} \lambda \lambda_{\circ} \nu: \mu \dot{\alpha} \lambda ı \tau \tau$, where we only have adverbial forms.

45 Meissner (2006:182-186) argues that there was no derivational link between adjectives in -vंs and compounds in - $\eta$ s. 
(e.g. $\tau \varepsilon \lambda \varepsilon^{\prime} \omega, \tau \varepsilon \lambda \varepsilon^{\prime} \omega$ 'to accomplish, fulfil', aor. $\varepsilon^{\prime} \tau \dot{\varepsilon} \lambda \varepsilon \sigma(\sigma) \alpha$ derived from $\left.\tau \dot{\varepsilon} \lambda \circ \varsigma\right) .{ }^{46}$ Originally the 'stative' verbs in $-\dot{\varepsilon} \omega$ had a zero grade root, cf. Lat. rubēre 'to be red' as opposed to the full grade in Gr. $\varepsilon \varepsilon^{\prime} \varepsilon \dot{\theta} \theta \omega$ 'to make red'. In Homeric verbs

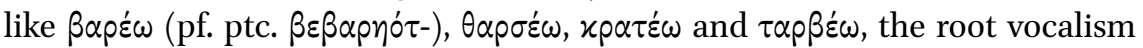
is equal to that of the accompanying $s$-stem nouns and adjectives (cf. Tucker 1990: $57-63$ ). However, since these $s$-stems originally had $e$-grade, the question arises whether the archaic category of 'statives' in $-\varepsilon \omega$ may have exerted analogical influence on derivationally associated formations such as $s$-stem adjectives. This indeed seems plausible, ${ }^{47}$ and the implication is that 'stative' verbs in - $\varepsilon$ ' $\omega$ (just like the adjectives in -v́ $\varsigma$ ) are candidates to show the regular outcome of ${ }^{*} r$.

On the other hand, as appears from Table 3, in Lesbian the leveling seems to have gone the other way: cf. $x p \varepsilon \tau \varepsilon \omega$ 'to have power' with the vocalism of

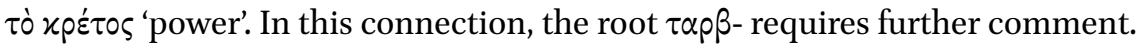

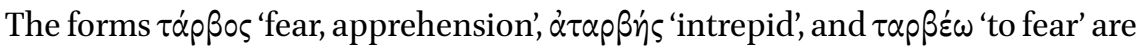
usually derived from a PIE verbal root ${ }^{*}$ terg ${ }^{w_{-}}$, continued in epic Skt. tarjati 'to threaten' (whose active voice may reflect an oppositional causative), Lat. torvus 'grim', and perhaps Hitt. tarkuuant- 'looking angrily'. 48 Since no $e$-grade forms

46 See Tucker (1990: 28-33), following Watkins (1971).

47 Cf. also $\theta \dot{\alpha} \mu \beta$ ऽ 'amazement, stupefaction' beside $\theta \alpha \mu \beta \varepsilon$ '́ $\omega, \theta \alpha \mu \beta \hat{\eta} \sigma \alpha$ l 'to be stupefied'. Tucker (1990: 42-43) proposes to derive the verb $\theta \alpha \mu \beta \varepsilon \dot{\varepsilon} \omega$ from the $s$-stem noun. The argument is that the root shape $\theta \alpha \mu \beta$ - cannot represent the development of a syllabic nasal (as in aor. ptc. $\tau \alpha \varphi \omega^{\prime} \nu$ 'stupefied'), and that it must therefore be a remodeling of * $\theta \varepsilon \mu \beta$-. That root shape, however, cannot be original in the stative verb in $-\varepsilon \omega$, but it would be at home in a neuter noun. However, a problem with this argument based on $\theta \alpha \mu \beta \varepsilon \dot{\varepsilon} \omega, \theta \alpha \mu \beta \hat{\eta} \sigma \alpha \mathrm{l}$ is that the reconstruction of the verb's phonetic developments remains uncertain. Szemerényi (1954) argued for comparing $\theta \alpha \mu \beta \varepsilon \varepsilon^{\prime} \omega$, aor. $\tau \alpha \varphi \omega$ ' with Goth. dumbs 'mute' and cognates (PGmc. *dumba-, PIE * $d^{h} e m b^{h_{-}}$). In subsequent discussions, Barton (1993) and Hackstein (2002: 237-238) have tried to account for the difference between $\theta \alpha \mu \beta$-, $\tau \alpha \varphi$ - and $\theta \eta \pi$ - The etymology is semantically plausible, but

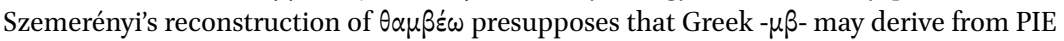

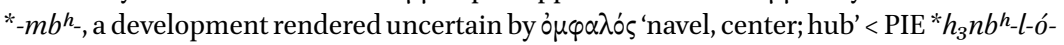
and $\dot{\alpha} \sigma \tau \varepsilon \mu \varphi \varepsilon \dot{\varsigma}$ 'firmly' (cf. Ved. stambh, and Van Beek 2018 for the reconstruction of $\dot{\alpha}-$ ). The explanation of $\tau \dot{\varepsilon} \theta \eta \pi \alpha$ instead of expected $\tau \dot{\varepsilon} \tau \eta \varphi \alpha$ (attested in Hsch.) given by Barton (1993) is not without problems either. Beekes (EDG s.v. $\theta \alpha \mu \beta \varepsilon \dot{\varepsilon} \omega)$ argues that the variation between $\theta \alpha \mu \beta-, \tau \alpha \varphi$ - and $\theta \eta \pi$ - can be understood if the words were borrowed from the Pre-Greek substrate: in such words, interchanges between stops and pre-nasalization are more frequently attested. Although this no longer seems likely to me in view of the archaic morphology of these verbs (cf. also Barton 1993: 2 with n. 3), the reconstruction of $\theta \alpha \mu \beta \varepsilon \dot{\varepsilon} \omega$ involves too many problems to base an account of the derivational history of statives in $-\varepsilon \dot{\varepsilon} \omega$ on it.

48 Hitt. tarkuuant- may alternatively be derived from * $d_{\diamond} \kappa$-uent- "with [angry] gaze", cf. Hom. i $\pi \delta \delta \rho \alpha$ 'looking askance.' The comparison of Middle Welsh tarfu 'to disturb, trouble, scare' with $\tau \alpha p \beta$ - is not without problems (cf. EDPC q.v.). 
of this root are directly attested in Greek, we must ask to what extent $\tau \alpha \rho \beta$ - can be seen as an analogical vocalization replacing the older $e$-grade allomorph; for instance, $\tau \dot{\alpha} \rho \beta 0 \varsigma$ might be viewed as a remodeling of older ${ }^{*} \tau \varepsilon \dot{\rho} \beta 0 \varsigma$ (thus Tucker 1990: 43). However, in this case we must ask in which formation the $a$-vocalism originated. The adjective attested to this root is $\tau \alpha p \beta \alpha \lambda \varepsilon$ cos 'fearful' ( $h$. Herm. 165, S. Tr. 957), but its formation is most probably secondary after the antonym

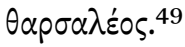

One might try to resolve this issue by positing an original adjective * $\operatorname{trg}^{w}-u^{-}-$ 'fearful', which would have yielded * $\tau \alpha \rho \beta u$ s and then imposed its $a$-vocalism on the other forms. ${ }^{50}$ However, this remains speculation, as there is no further evidence for such a form. Moreover, it is quite uncertain that the neuter $\tau \dot{\alpha} p-$

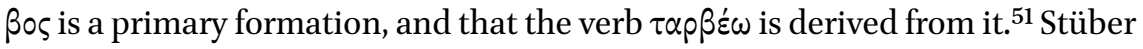
(2002: 47-48) argues that $\tau \alpha \rho \beta \varepsilon \dot{\varepsilon} \omega$ is the oldest formation, and that zero grade root was introduced from there into the $s$-stem noun. In support of this, Meissner (2006: 94) suggests that $\tau \dot{\alpha} p \beta 0 \varsigma$, which in Homer occurs only in Book 24 of the Iliad, may actually be a backformation from $\alpha \tau \alpha \rho \beta \eta \dot{\zeta}$ (or $\left.\tau \alpha \rho \beta \varepsilon \tilde{\varepsilon}^{\omega} \omega\right)$ because these forms are much more frequent in Homer. Thus, we may suspect that $\tau \alpha \rho-$

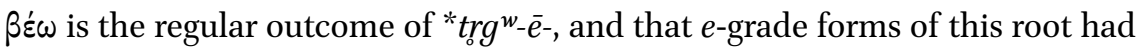
been lost before the vocalization of ${ }^{*} r$.

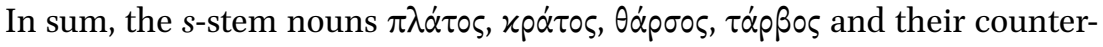
parts in second compound members cannot be used as evidence for the regular development of the syllabic liquids, as their vocalism may have been influenced by that of $u$-stem adjectives ( $\pi \lambda \alpha \tau \dot{\tau} \varsigma, \chi \rho \alpha \tau \dot{v} \varsigma$, cf. also $\theta p \alpha \sigma \dot{\varsigma} \varsigma$ ) or inchoative verbs in $-\dot{\varepsilon} \omega\left(\theta \alpha \rho \sigma \varepsilon^{\prime} \omega, \tau \alpha \rho \beta \varepsilon^{\prime} \omega\right)$. These primary and unproductive formations constitute the main body of evidence for the vocalization of ${ }^{*} r$. In addition to $u$-stem adjectives, there are also productive thematic adjective types in - вpós and $-\alpha \lambda \varepsilon$ ćs. Establishing the derivational prehistory of these forms will put us in a better position to judge their relevance for the vocalization of ${ }^{*} r$.

\subsubsection{Replacement of $u$-stem Adjectives}

In Greek, $u$-stem adjectives are unproductive generally, and in Epic Greek they even seem to be avoided. ${ }^{2}$ For instance, the inherited form $\beta p \alpha \chi ن$ 's 'short' is

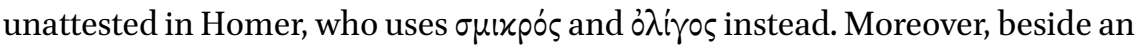

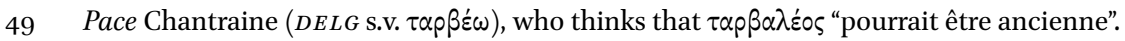

50 As I did in Van Beek 2013: 92.

$5^{1} \quad$ LIV ${ }^{2} 632$, Anm. 1.

$5^{2}$ In Classical Attic prose (and presumably in the spoken vernacular), only the following 14

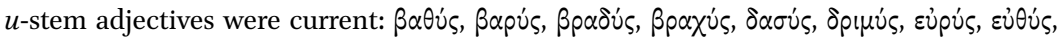

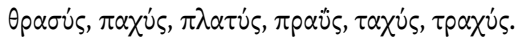




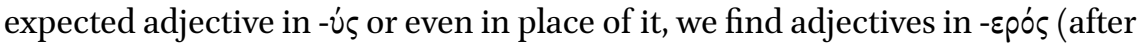

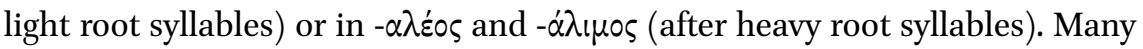
such forms are found in Epic Greek only, and they occasionally penetrated into other poetic genres.

A key factor accounting for the underrepresentation of adjectives in -v́s in Epic Greek is related to meter and verse composition. Let us consider some instances of suffix competition. While xpatús appears only in one single name-

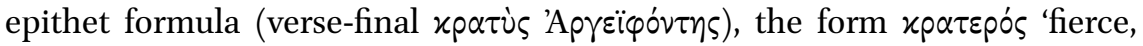
vehement, strong, etc.' is extremely frequent. Another well-known pair is $\gamma \lambda u-$ xús 'sweet, pleasant' beside $\gamma \lambda \nu x \varepsilon p o ́ s .{ }^{53}$ In Classical prose there is no trace of

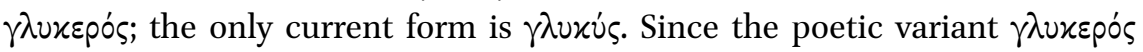
is highly convenient in dactylic rhythms, it may well have an artificial origin within Epic Greek. Indeed, in Homer $\gamma \lambda u x v$ s occurs exclusively in the strong

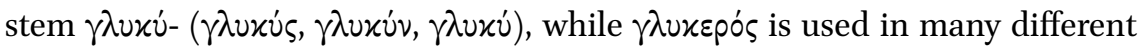
cases. This is related in part to the problematic shape of various case forms of

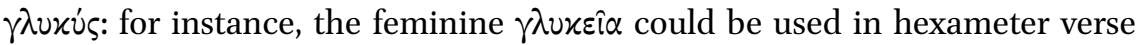
only with tautosyllabic scansion of muta cum liquida, which is still relatively rare in Homer and was probably avoided to a large degree (see sections 6.5 and 6.6). A more general problem with adjectives in -ús is the fact that the metrical shape of the feminine forms is different from the masculine/neuter for every single case form. Poets frequently resorted to inflection and/or transformation of phraseological material, and in such cases (for instance when an adjective had to modify a noun with a different gender) it was convenient to keep it in

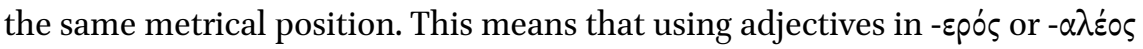
gave epic poets much more flexibility than using adjectives in -vंs, with their suffix ablaut and metrically different feminine formation. ${ }^{54}$ Given this metrical

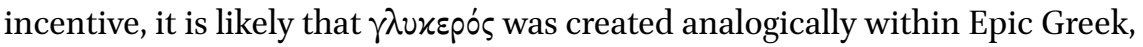

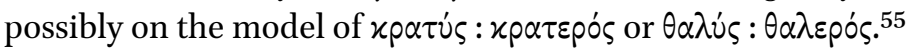

53 Lamberterie (1990: 470) shows that there is no clear semantic difference between $\gamma \lambda u x v ́ \varsigma$

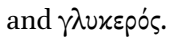

54 Some Homeric $u$-stem adjectives with a heavy root syllable are very numerous as tokens, e.g. ó $\xi \dot{v} \varsigma$ and $\dot{\omega} x \dot{v} \varsigma$, but this is mainly due to their frequent occurrence in formulaic cola (cf.

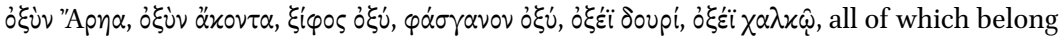
to traditional war narrative).

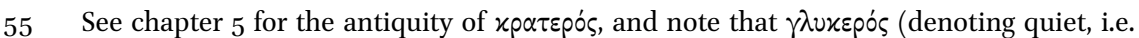
non-violent, activities) was more or less its antonym. Also, note that $\theta \alpha \lambda \varepsilon p o ́ s ~ ' a b u n d a n t '$ is probably an inner-Greek innovation, too: the correspondence with Arm. dalar 'green, fresh' is rightly criticized by Clackson (1994:118-120), who notes the semantic distance and

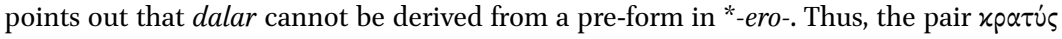

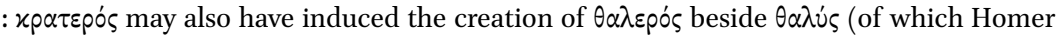


As for the adjectives in $-\alpha \lambda \varepsilon$ Éoร, although their origin remains hard to establish, it is widely accepted that they were productive synchronically beside $s$ stem nouns. ${ }^{56}$ In Homer, we find examples like $x \varepsilon p \delta \alpha \lambda \varepsilon$ é ' 'wily' beside $x \varepsilon$ é $\delta \circ \varsigma$ 'ruse; profit' and the frequent $\alpha$ pra $\lambda$ ह̇os 'painful; difficult' (dissimilated from

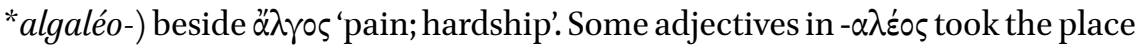
of an original $u$-stem adjective, or were created in order to supply for its loss.

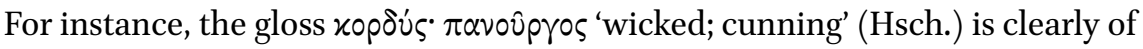
non-Ionic origin, and an archaism. The lack of a corresponding adjective * xap$\delta$ ós in Ionic-Attic suggests that the $u$-stem form was lost before $x \varepsilon p \delta \alpha \lambda \chi_{\varepsilon} \circ \varsigma$ was derived from $\chi \varepsilon \dot{\rho} \rho \delta \circ$, or at least before * $\varkappa a p \delta u ́ s$ had the chance to influence the vocalism of the other forms. ${ }^{57}$

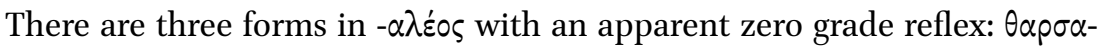

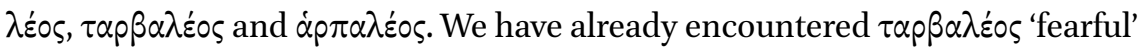

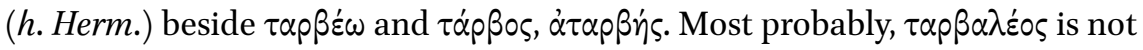
an old adjective (pace DELG s.v.). Instead, it was derived from $\tau \dot{\alpha} p \beta 0 \varsigma$, and the latter's vocalism was taken over from the stative verb $\tau \alpha \rho \beta \varepsilon \varepsilon^{\prime} \omega$ and/or the dever-

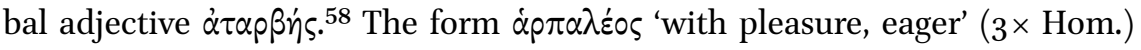
is from *ualpaleo- by liquid dissimilation (cf. $\alpha \lambda \pi \alpha \lambda \varepsilon \dot{\varepsilon} \sigma \cdot \cdot \dot{\alpha} \gamma \alpha \pi \eta \tau \sigma^{\circ}$ 'cherished', Hsch.), containing the root of ह̇ $\lambda \pi 0 \mu \alpha \mathrm{l}$ 'to reckon; hope, expect'. In this case, no neuter abstract is attested from which *ualpaleo- could be derived. However, $a$ vocalism is also found in the superlative $\alpha \ddot{\lambda} \pi \iota \tau \tau \circ \varsigma$ (A., Pi.) and may stem from a primary adjectival formation, such as a $u$-stem adjective. ${ }^{59}$

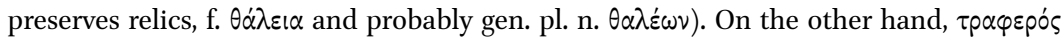
'thick, solid' was derived not from the adjective $\tau \alpha \rho \varphi v$ s (which has a different vowel slot

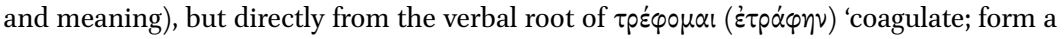
crust': see section 4.3.2 below.

$5^{6} \quad$ E.g. Tucker (1990: $55^{-56}$ ): "their vocalism or phonological shape suggests that they were created on the basis of $s$-stem nouns". Rau (2009: $128 \mathrm{n}$. 9) observes that this process "generally results from the derivational association of morphologically unrelated formations". A number of adjectives in $-\alpha \lambda \varepsilon$ É $\varsigma$ acquired the suffix by contamination with semantically

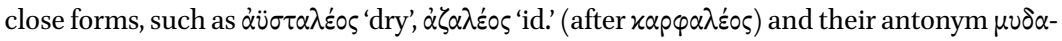

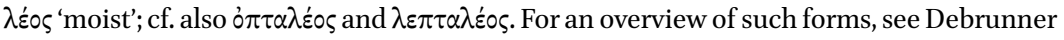
(1917: 165-168).

57 For this interpretation of xopóv, and on the question why the adjective was lost so early, see Lamberterie (1990: 867-874), following R. Schmitt. The reflex -op- points to an Aeolic or Arcado-Cyprian origin.

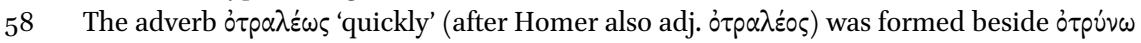

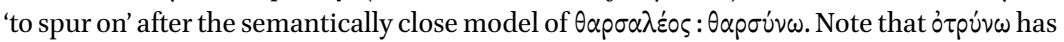
no convincing etymology (the traditional comparison with Skt. tvarate and OHG dweran is criticized by Beekes, $E D G$ s.v. ò $\tau \rho \alpha \lambda \varepsilon \dot{\varepsilon} \omega \varsigma)$.

These forms and their reconstruction are further discussed in section 10.2.1. 
An important form is $\theta \alpha \rho \sigma \alpha \lambda \varepsilon$ ह́o 'persevering, audacious; confident' (Hom.+;

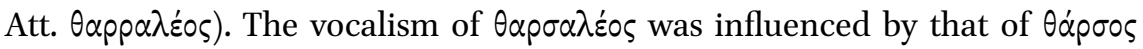
(from which it was derived) after the latter had replaced the older form * ${ }^{*}$ éбos. The question is how the last-mentioned replacement could take place if $\theta \alpha \rho \sigma \alpha \lambda \varepsilon$ ćs did not yet exist. An archaic adjective formation is $\theta p \alpha \sigma u$ s 'bold, reckless', but this has a different root shape $\theta p \alpha \sigma-$. As I will argue below, it is likely that another form * $\theta \alpha \rho \sigma u$ ' 'daring, confident' once existed in Proto-Ionic, and that this form influenced the vocalism of $\theta$ ápoos before it lost currency and was ousted by $\theta \alpha \rho \sigma \alpha \lambda \varepsilon_{\text {ŕo }} .00$

In sum, the evidence suggests that the vocalism of forms in $-\alpha \lambda$ Éo

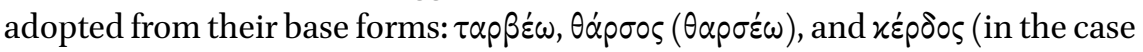
of $\dot{\alpha} \rho \pi \alpha \lambda \dot{\varepsilon} \circ \varsigma$, the base form is unknown). It is therefore not possible to use the vocalism of $\tau \alpha p \beta \alpha \lambda \varepsilon \dot{\varepsilon} \circ, \dot{\alpha} p \pi \alpha \lambda \varepsilon \dot{\varepsilon} \circ \varsigma$ and $\theta \alpha \rho \sigma \alpha \lambda \varepsilon \dot{\varepsilon} \circ \varsigma$ as evidence for the regular outcome of liquid vocalization.

\subsubsection{Derivational History of the Factitives in - $v$ vw}

Homer has a remarkable asymmetry in root shape between the stative verb

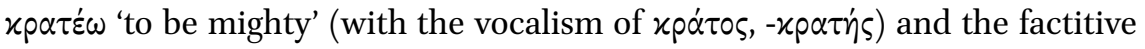

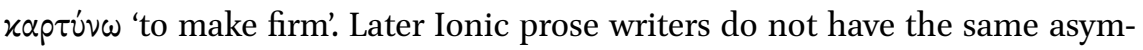

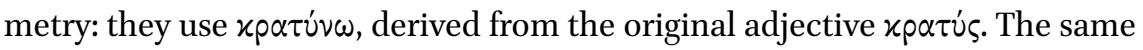
derivation cannot explain $x \alpha \rho \tau u ́ v \omega:$ as far as we know, there was never a by-

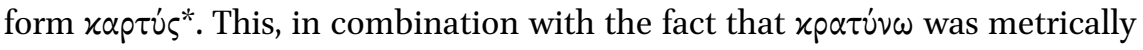
inconvenient in Epic Greek (it necessitated tautosyllabic scansion of muta cum

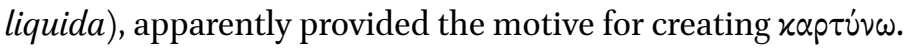

However, was it possible to replace - $\rho \alpha$ - with - $\alpha \rho$ - just like that? Most scholars seem to make this assumption. ${ }^{61}$ I suspect that mere metrical convenience was not a sufficient reason for swapping the liquid and the vowel. The reason is that the occurrence or non-occurrence of doublets often cannot be predicted, as appears from the following examples:

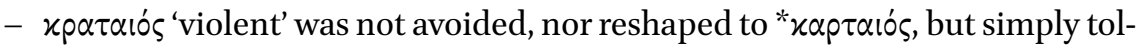
erated (with its aberrant scansion) in the old formula Moîp $\alpha$ xp $\alpha \alpha i \eta \dot{n}$.

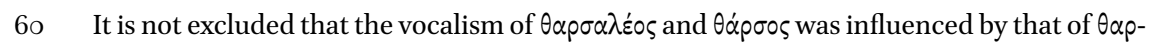
$\sigma \varepsilon \dot{\varepsilon} \omega$, which could directly reflect an inherited 'stative' * $t^{h}{ }_{r} s-\bar{e}$-. However, the derivation of

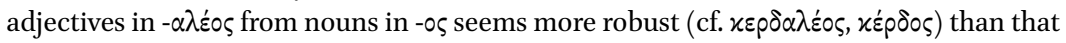
from verbs in $-\varepsilon \dot{\epsilon} \omega$.

61 This view is widespread, see e.g. the casual remark by Strunk (1975: 286), regarding $x$ ap$\tau \dot{v} v \omega$, that "inlautendes $-\alpha \rho-<{ }^{*}-r$ - vor Konsonant (...) auch sonst gelegentlich statt oder neben - $\alpha$ - vorkommt." 
- The superlative $x p \alpha \dot{\tau} \iota \sigma \tau \circ$, on the other hand, is avoided in Homer and replaced by $x \dot{\alpha} \rho \tau \imath \sigma \tau ం \varsigma$ 'fiercest'. 62

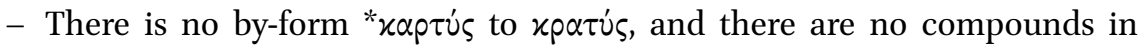

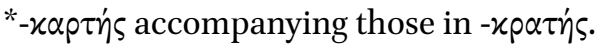

- The aorist ( $\dot{\varepsilon}) x p \alpha$ ' $\eta \eta \alpha$ 'gained victory/the upper hand' is absent from Homer. Since this form is common in later poetry, and given that other members of the small group of Homeric stative verbs in - $\varepsilon \omega$ are frequent especially in the aorist stem (cf. Tucker 199o: 39), it is natural to suppose that epic poets avoided $(\dot{\varepsilon}) x p \dot{\alpha} \tau \eta \sigma \alpha$ for metrical reasons. They never created an alternative form $x \alpha \dot{\alpha} \rho \tau \eta \alpha^{*}$, even if this would have been metrically useful. ${ }^{63}$

Apparently, simply replacing - $\rho \alpha$ - with $-\alpha \rho$ - was not always a viable option. My working hypothesis is that by-forms with - $\rho \alpha$ - or $-\alpha \rho$ - could be created only if they were the product of an inner-epic proportional analogy or derivation. In

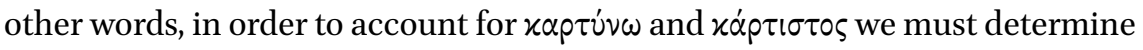
a model and a motive. ${ }^{64}$

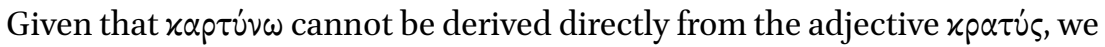
have to ask whether the derivation of verbs in -vvv from neuter abstracts was already productive in Homer. Tucker (1981) discusses the spread of the Greek factitive verbs in -ó $\omega$, - $v \omega \omega$, and - $\alpha i v \omega .{ }^{65}$ Among the factitive verbs in - $v \omega \omega$ she distinguishes three types according to the base form:

(1) based on $u$-stem adjectives ( $\beta$ apús 'heavy' $\rightarrow$ Hom. $\beta$ apúvw 'to weigh down on')

(2) based on $s$-stem nouns ( $\mu \hat{x} x \circ \varsigma^{\prime}$ length' $\rightarrow$ Att. $\mu \eta x \dot{v} v \omega$ 'to lengthen')

(3) based on $o$-stem adjectives ( $\lambda \varepsilon \pi \tau$ 'ó ' 'thin, delicate' $\rightarrow$ Att. $\lambda \varepsilon \pi \tau \dot{v} v \omega$ 'to make thin').

As the chronology of the attestations confirms, the - $v v \omega$ factitives originated beside $u$-stem adjectives (cf. also Hom. $\beta \alpha \theta \dot{v} v \omega, i \theta \dot{v} v \omega$ ). Therefore, types (2) and (3) are generally considered to be later derivational patterns.

$62 \quad$ An explanation for these distributions is proposed in chapter 6 .

63 However, creating * $(\dot{\varepsilon}) x \alpha \dot{\alpha} \tau \tau \emptyset \alpha$ was not strictly necessary from the viewpoint of verse composition, as the meaning 'to obtain victory' was expressed already by metrically equivalent

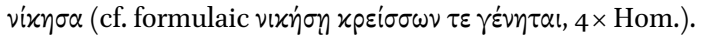

64 The absence of * $(\dot{\varepsilon}) x \alpha \dot{\alpha} \rho \eta \eta \sigma \alpha$ can be explained if we accept that $x \rho \alpha \tau \dot{\varepsilon} \omega$ functioned, from a synchronic viewpoint, as a primary formation. I now disagree with Tucker's suggestion (1990: 62-67) that statives in - $\varepsilon \omega$ could be derived from $s$-stem compounds, and revoke what I said about this in Van Beek 2013: 92. In fact, if compounded adjectives in - $\eta$ s are derived from statives in - $\varepsilon \omega$, as I now think, the absence of * $\chi \alpha \rho \tau \varepsilon \omega$ accounts directly for the absence of compounds in *-«aptris.

65 The classic study of Greek denominatives is Fraenkel (1906). 
Derivation type (2), factitives in - $v \omega$ beside $s$-stem neuters, is clearly productive in Attic. Tucker (1990) argues that this type started to become productive already in Homer. She remarks (1990: 47) that in Homer there are "two - vvw

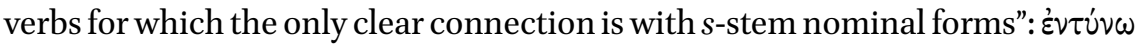

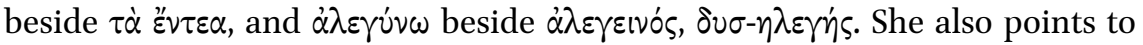
$\theta \alpha \rho \sigma u v \omega \omega$ and $\varkappa \alpha p \tau \dot{v} v \omega$ as further possible Homeric examples of derivations from $s$-stems, as the adjectives $\theta p \alpha \sigma u ́ s$ and xpa ús have a different vowel slot, while the correct vowel slot is found in the corresponding $s$-stem neuters $\theta \dot{\alpha} p \sigma o s$ and

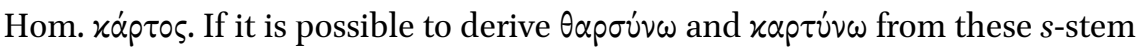
nouns, the distribution of - $\rho \alpha$ - and - $\alpha \rho$ - over the attested forms would indeed make sense. ${ }^{66}$

Although this is definitely an improvement over the view that the interchange between - $\rho \alpha$ - and - $\alpha p$-is randomly induced by metrical utility, there are serious problems with Tucker's concrete suggestions. First of all, the evidence

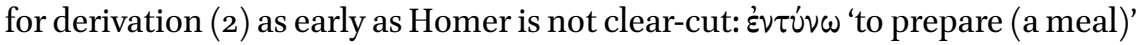
cannot have been reanalyzed as derived from $\tau \dot{\alpha}$ हैv $v \varepsilon \alpha$, which is a lexicalized form with a concrete meaning 'gear, tools, equipment', especially 'arms. ${ }^{67}$ The second example $\alpha \lambda \varepsilon \gamma \dot{v} v \omega$ 'to attend a meal' cannot count as evidence either, because $\alpha \lambda \varepsilon \gamma \varepsilon v v o ́ s$ and $\delta \nu \sigma-\eta \lambda \varepsilon \gamma \dot{\eta} \varsigma$ have a markedly different meaning, 'hard to deal with'. It is more likely that $\dot{\alpha} \lambda \varepsilon \gamma \dot{v} v \omega$ is a contamination between $\dot{\alpha} \lambda \varepsilon \dot{\gamma} \gamma$ 'to

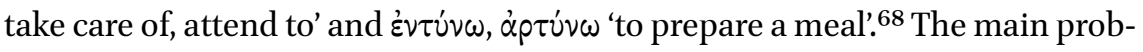
lem is that Tucker is unable to point out a convincing pivotal form, i.e. a verb in - $v v \omega$ beside an $s$-stem neuter and a $u$-stem adjective. Her best example is $\tau \dot{0}$

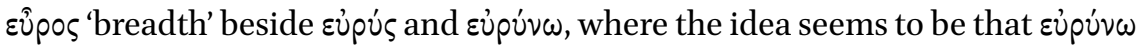
was originally derived from eủpús, but secondarily reanalyzed as derived from

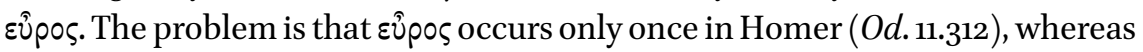
Eủpús is frequent. It is questionable whether a transparent derivation eủpús $\rightarrow$

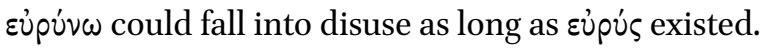

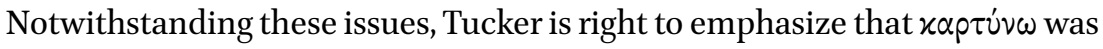
not derived directly from xpa ús (because the latter has a different vowel slot),

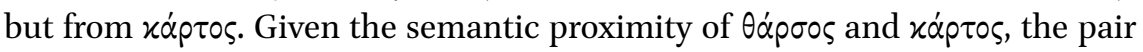
$\theta \alpha \rho \sigma 0 ́ v \omega: \theta \alpha$ p $\sigma 0 \varsigma$ would provide an excellent model for the derivation of $x \alpha p-$ $\tau \dot{v} v \omega$. But what about the pair $\theta \alpha \rho \sigma \dot{v} \omega \omega: \theta \dot{\alpha} \rho \sigma o \zeta$ itself? A priori, one expects a sec-

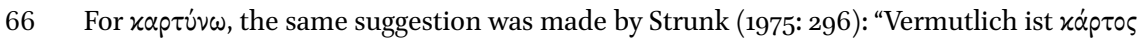
sogar die wirkliche morphologische Basis für die epische Verbalableitung."

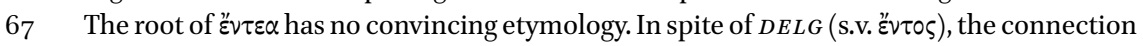
with $\alpha v v^{\prime} \omega$ 'to accomplish' < ${ }^{*} s n h_{2}-u$ - is difficult to maintain because that root ended in a laryngeal.

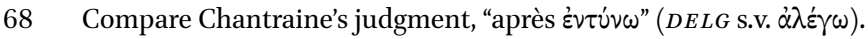


ondary association of $s$-stem nouns and -vंvw verbs to have started in one or two (preferably frequent) cases where an original $u$-stem adjective has been lost or replaced by a different form. Subsequently, a derivational relation between a

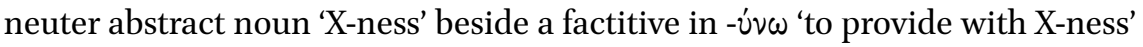
could easily be established. The root $\theta \alpha \rho \sigma$ - would be an excellent candidate for this reanalysis, because the base form " ${ }^{*}{ }^{h} r s u$ - had turned into $\theta p \alpha \sigma \dot{v}$, with the wrong vowel slot. Moreover, there are independent indications that $\theta \alpha p \sigma \alpha \lambda \varepsilon$ É ousted an older form * $\theta \alpha \rho \sigma u ́ s$ (see section 4.5). Finally, the derivation $\theta \dot{\alpha} \rho \sigma o \varsigma \rightarrow$ $\theta \alpha \rho \sigma u ́ v \omega$ 'to encourage, reassure' is transparent in Homeric Greek, and $\theta \alpha \rho \sigma u ́ v \omega$

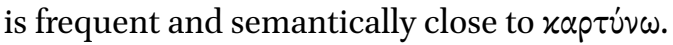

In sum: the later, Classical derivational pattern $\mu \eta \hat{x}$ $\circ \rightarrow \mu \eta x \dot{v} v \omega$ has not yet acquired full productivity in Homeric Greek, but it is already present in an embryonic stage in the pair $\theta \dot{\alpha}$ poos : $\theta \alpha \rho \sigma u ́ v \omega$, combined with the absence of an adjective * $\theta \alpha \rho \sigma u ́ \varsigma$.

\subsection{Reflexes of ${ }^{*} r$ and ${ }^{*} l i$ in the $u$-stem Adjectives}

The following $u$-stem adjectives with a root shape $C L a C$ - are attested in Home-

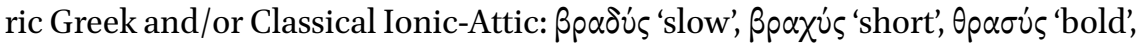

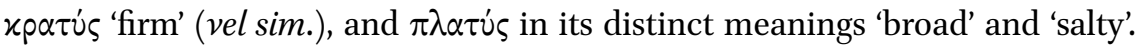
In Homer, none of these adjectives is frequent, and $\beta p \alpha \chi \dot{v} \varsigma$ is even absent; as we have seen, this tendency can be ascribed to the metrical inconvenience of ablauting paradigms. An adjective $\beta \lambda \alpha \delta$ 's 'weak' is frequently cited; it is attested only as a gloss $\beta \lambda \alpha \delta \varepsilon i \hat{\varsigma}$ (Hsch.), along with a few other glosses with $\beta \lambda \alpha \delta$.

In the handbooks, a number of these forms are adduced as evidence for the regular development of the syllabic liquids. ${ }^{69}$ Given that the evidence is so meagre, it is remarkable that these treatments systematically ignore another $u$-stem adjective with an original syllabic liquid: $\tau \alpha \rho \varphi \cup$ s 'numerous'. Derived

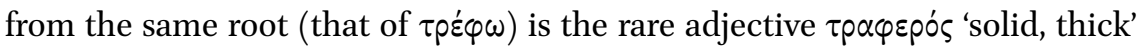

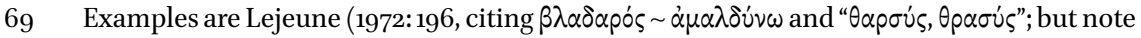
that the first form $\theta \alpha \rho \sigma \dot{\varsigma} \varsigma$ is not directly attested), Rix (1992: 65, citing $\left.\pi \lambda \alpha \tau \tau^{\prime} \varsigma\right)$, and Sihler

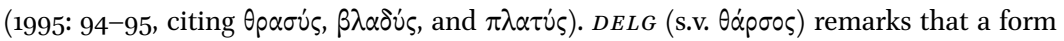

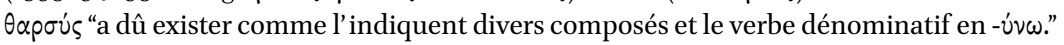
As we will see below, this may well be true, but the form should be asterisked in any case.

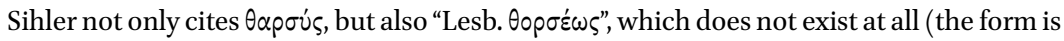
correctly cited as $\theta p \circ \sigma \varepsilon \omega \varsigma$ by Lejeune (1972: l.c.), and is attested as such only in Joh. Gramm. 2.11, where it is labelled Aeolic). 


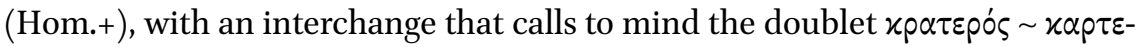

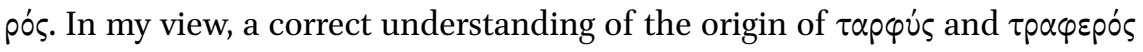
is crucial for establishing the regular development of ${ }^{*} r$, and we will therefore turn to these forms first. There are two questions to be answered: Why do we find - $\alpha \rho$ - in $\tau \alpha \rho \varphi v ́$, as against - $\rho \alpha$ - or - $\lambda \alpha$ - in all other $u$-stem forms? ${ }^{70}$ And: What

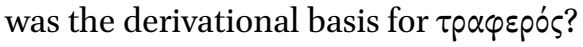

\subsection{1 $\quad{ }^{*} r>\alpha \rho$ is Regular in $\tau \alpha \rho \varphi v$}

The Homeric adjective $\tau \alpha p \varphi \dot{s}$ 'thick, dense, close together' modifies nouns

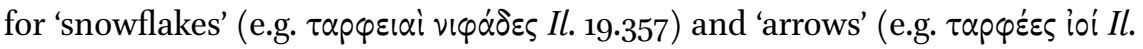

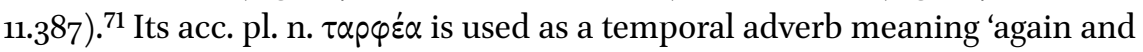

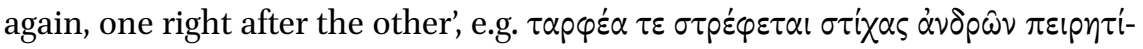
$\zeta \omega \nu$, "(the boar) turns round again and again, putting the ranks of men to the test" (Il. 12.47). Lamberterie (1990: 676-68o) gives solid arguments for deriving

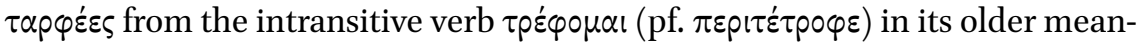
ing 'to form a layer, become thick, coagulate' (Hom.+). ${ }^{72}$ The development of meaning from 'thick' to 'frequent' is common, too. For instance, English 'thick' may also be used as an adjective or adverb denoting a frequent occurrence, as in thick and fast; in Dutch, dikwijls means 'frequently, often'.

A striking fact about the attested forms and their meanings is that Homer appears to have used $\tau \alpha \rho \varphi \varepsilon ́ \varepsilon \zeta, \tau \alpha \rho \varphi \varepsilon\left\llcorner\alpha^{\prime}\right.$ as a plurale tantum. This usage is continued in post-Homeric poetry. ${ }^{73}$ The singular form $\tau \alpha \rho \varphi v ́ s$ is attested in literary texts twice in Aeschylus, and much later once in Lucian, in a parody; other Hellenistic poets again use only the plural form. ${ }^{74}$ Another remarkable feature is the accentuation of the feminine $\tau \alpha \rho \varphi \varepsilon i \alpha i$, which is paralleled in the synonymous plurale tantum $\theta \alpha \mu \varepsilon \varepsilon \varepsilon s, \theta \alpha \mu \varepsilon ı \alpha^{\prime}$. This accentuation is clearly a retained

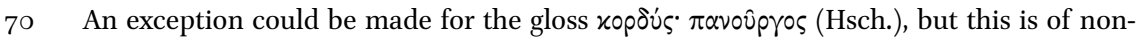
Ionic-Attic origin: see above. As I have argued in section 2.2, the Mycenaean form ta-pa-e$o$-te is too uncertain to be used in this discussion.

71 Lamberterie (1990: 665-666) remarks that this use is intimately related with that as a qualification of snowflakes, the image being that of a rain of arrows.

72 An extensive study of the semantics of $\tau \rho \varepsilon \varepsilon \varphi \omega$ is Demont (1978).

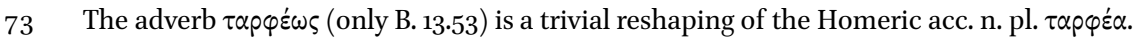

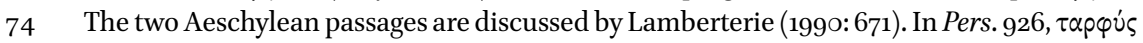

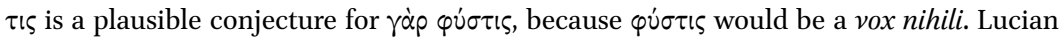
uses the gen. sg. $\tau \alpha \rho \varphi \varepsilon^{\prime} \circ \varsigma$ modifying $\varepsilon^{\prime} \chi \dot{\varepsilon} \tau \lambda \eta$. Remarkably, in all three cases the adjective modifies a feminine noun. Moreover, note that in both $\tau \alpha \rho \varphi \dot{v} \varsigma$... $\theta$ pi ' 'thick hair' (A. Sept. 535) and the conjecture $\tau \alpha \rho \varphi v ́ \varsigma \tau \iota \varsigma \mu \nu \rho i \dot{\alpha} \alpha \dot{\alpha} \delta \rho \omega \hat{\nu}$ 'thronging myriads of men' (A. Pers. 926), $\tau \alpha \rho \varphi \dot{s}$ qualifies a singular noun with plural or collective sense. I therefore claimed in Van Beek 2013: 101 that the singular of $\tau \alpha \rho \varphi v ́ \varsigma$ was a secondary creation by Aeschylus. I still consider this plausible, but there is no need to insist on it. 
archaism: presumably, it was not aligned with the productive type of accentua-

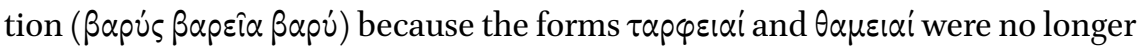
current in the spoken language.

Most dictionaries (e.g. $L S J$ ) cite another form with the root shape $\tau \alpha \rho \varphi$-: the

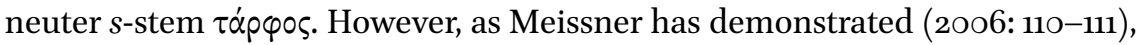
the singular $\tau \dot{\alpha} p \varphi \circ \varsigma$ is only found in ancient grammarians, commentaries and scholia; all real attestations in primary sources are in the plural. ${ }^{75} \mathrm{It}$ is therefore possible to assume that these forms are substantivizations of the $u$-stem adjective, with a corresponding accent retraction. ${ }^{76}$ This hypothesis is corroborated, as Meissner remarks, by the parallel case of $\tau \dot{\alpha} \beta \rho \alpha \dot{\alpha} \varepsilon \alpha$, attested from Thucydides and Herodotus onwards in the lexicalized meaning 'shoal, sandbank'. The absence of contraction of $-\varepsilon \alpha$ in the Attic form proves that we are dealing with an old $u$-stem form, with subsequent retraction of the accent accompanying the lexicalization as a substantive. ${ }^{77}$ Moreover, the expression $\varepsilon^{2} \nu \tau \dot{\alpha} \rho \varphi \varepsilon \sigma \nu \nu$ ü $\lambda \eta \varsigma$ 'in the thick (= dense parts) of the forest' (Hom.) has a neat phraseological parallel in ह่v $\beta p \alpha ́ x \varepsilon \sigma \iota \lambda i \mu \nu \eta s^{\prime}$ 'in the shallows (= shallow parts) of the lagoon', attested in Hdt. 4.179.

We may conclude that $\tau \dot{\alpha} p \varphi \circ \varsigma$ can be ignored for purposes of reconstruction. This puts us in a better position to judge the origin of - $\alpha p$ - in $\tau \alpha p \varphi v \dot{s}$. In section 1.4, a number of previous attempts to explain the reflex $\tau \alpha \rho \varphi$ - were discussed, such as secondary ablaut (Kuryłowicz), or metrically-induced metathesis (Güntert). All such proposals illustrate the embarrassment of earlier scholars concerning the reflex - $\alpha p$-. In reality, in view of the full-grade slot of the root ( $\tau \rho \varepsilon \dot{\varphi} \varphi$ o $\alpha$ l, PIE ${ }^{*} d^{h} r e b^{h_{-}}$), the outcome $\tau \alpha \rho \varphi$ - cannot have an analogical origin.

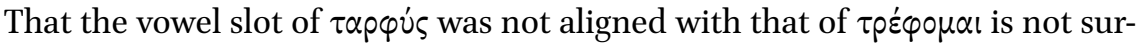
prising, given the lexicalized nature of this adjective. ${ }^{78}$ Apparently, it did not

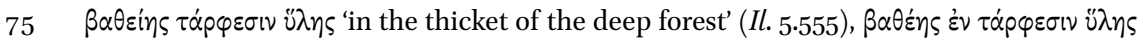

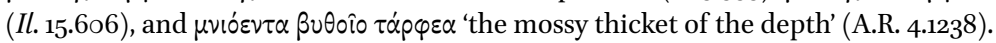

76 Already before Homer, following the loss of intervocalic digamma, the $u$-stem adjectives in Ionic-Attic had generalized the dat. pl. ending - $\varepsilon \sigma \iota$ by a proportional analogy with the $s$-stems, with which they shared the nom. pl. n. in $-\varepsilon \alpha$.

77 From an older $s$-stem form, one would expect Att. $\beta p \alpha \dot{\alpha} \chi \eta$ (Meissner 2006: 108-109).

78 In Van Beek 2013: 101, I claimed that $\tau \alpha \rho \varphi$ - was protected from analogical replacement by $\tau p \alpha \varphi$ - because $\tau \alpha \rho \varphi \varepsilon \varepsilon \varepsilon \varsigma$ would have become a plurale tantum early on. I explained the dif-

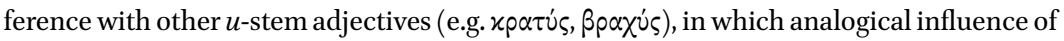
the full grade did take place, with the assumption that paradigmatic root ablaut was still preserved in the singular paradigm when ${ }^{*} r$ was eliminated in Proto-Ionic. However, while

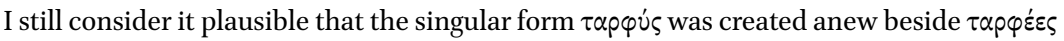
after Homer (cf. above), I now renounce on the idea that the adjectives in -v́ retained paradigmatic root ablaut until as late as Proto-Ionic. 
undergo the influence of comparative or superlative forms: no such forms are attested for $\tau \alpha \rho \varphi v$ s, which may well have to do with its lexical semantics. ${ }^{79}$

We may conclude that $\tau \alpha \rho \varphi \varepsilon^{\prime} \varepsilon \varsigma$ (and its feminine $\tau \alpha \rho \varphi \varepsilon ı \alpha^{\prime}$, with relic accentuation) is the regular outcome of PGr. ${ }^{*} t^{h} r p^{h} e_{\text {é }}$ es. It is a prime piece of evidence for a regular development ${ }^{*} r>-\alpha p$ - in Proto-Ionic. ${ }^{80}$

\subsubsection{Derivation of Hom. трафspós}

Before the end of the classical period, the adjective трацвpós is attested only

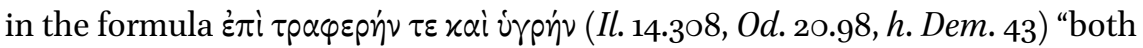
over the solid land and the waters of the sea" (Wyatt 1999), literally "over the

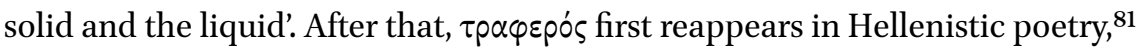
and Oppian is especially fond of the word in his Halieutica.

Ancient scholia and lexica explain $\tau \rho \alpha \varphi \varepsilon p \eta$ by remarking that $\theta \rho \varepsilon \dot{\psi} \psi \alpha l$ is another word for $\pi \hat{\eta} \xi \alpha$, which may mean "make solid or stiff, esp. of liquids: freeze, ... curdle, ..." (LSJ mg. III). ${ }^{82}$ That the juxtaposed forms íypós and $\tau p \alpha-$

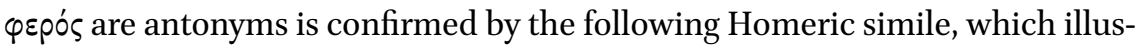
trates how Paeëon heals wounded Ares:

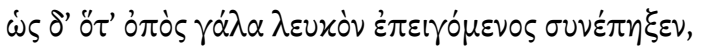

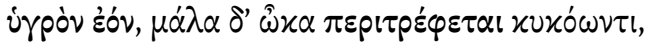

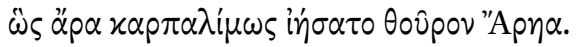

Il. $5 \cdot 902-904$

Even as the juice of the fig speedily makes to grow thick the white milk that is liquid, but is quickly curdled as a man stirs it, even so swiftly healed he furious Ares.

tr. WYATT 1999

79 This is not to say that no comparative or superlative forms of $\tau \alpha \rho \varphi v$ s ever existed, but only that they were apparently too marginal (at the relevant time) to influence the vocalization of the adjectival root. Since being clotted or curdled is an aggregation state, its meaning does not easily lend itself to the expression of degree: what matters most is the binary opposition between 'thick' and 'liquid'.

8o Incidentally, note that the absence of forms like * $\tau p \alpha \varphi \varepsilon$ เ í with muta cum liquida scansion (which would be the expected outcome of ${ }^{*} t^{h}{ }^{r} p^{h}$ euiai in Epic Greek, according to the scenario to be put forward in chapter 6 ) can be ascribed to the availability of the synonymous form $\theta \alpha \mu \varepsilon ı \alpha i ́$.

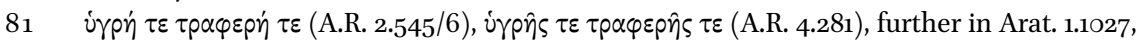
Theoc. 21.18 and 44, in the last passage in the meaning 'well-fed, thick, fat'.

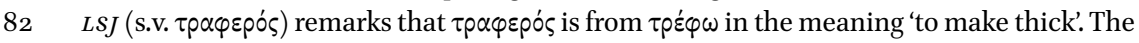

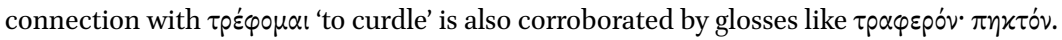

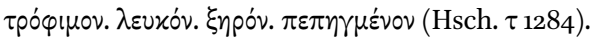




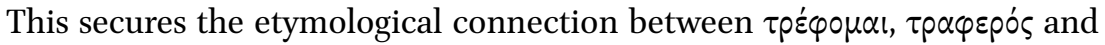

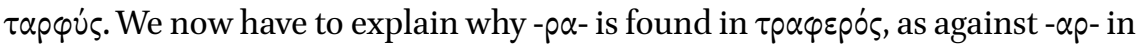

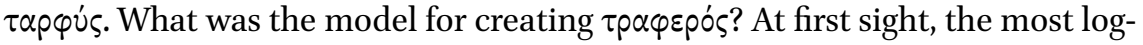
ical option would be a proportional analogy with the $u$-stem adjective, given

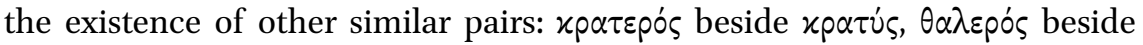
$\left.{ }^{*}\right) \theta \alpha \lambda u$ s, and $\gamma \lambda u x \varepsilon p o ́ s$ beside $\gamma \lambda u x v$ s. However, the shape of the $u$-stem adjective is $\tau \alpha \rho \varphi v$ s, not * $\tau p \alpha \varphi v$ s, and this means that the model breaks down. Even if one were to assume a prolonged retention of root ablaut in $u$-stem adjectives, it would not be feasible to argue that the root allomorphs $\tau \alpha \rho \varphi$ - and $\tau p \alpha \varphi$ - once coexisted within the same paradigm.

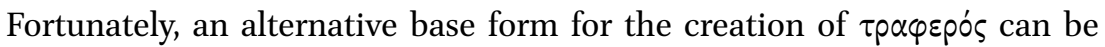
pointed out: the verbal stem. A number of adjectives in -epós pair with pri-

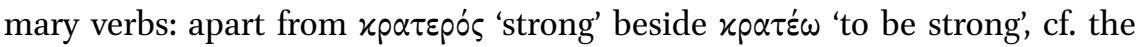

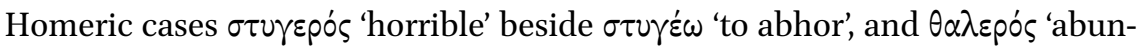
dant' beside $\theta \dot{\alpha} \lambda \omega \omega$ 'to be abundant'. Remarkably, after Homer we find a cou-

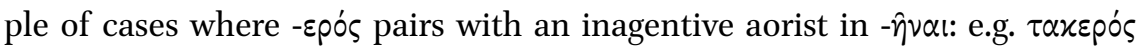

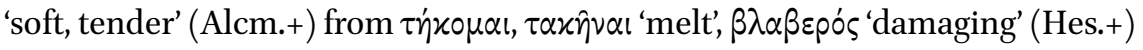

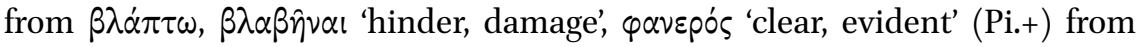

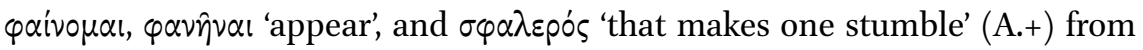
$\sigma \varphi \alpha \lambda \lambda \omega, \sigma \varphi \alpha \lambda \eta \hat{v}$ al '(make) stumble' (Hom.+). Apparently, the adjectival suffix

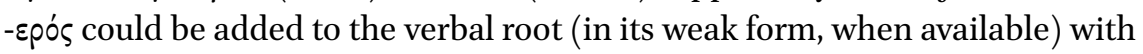
some productivity.

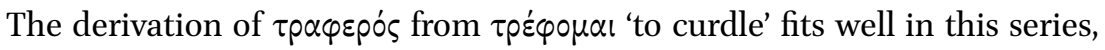
as the verb has an old intransitive aorist $\dot{\varepsilon} \tau p \dot{\alpha} \varphi \eta \nu$. From a semantic perspec-

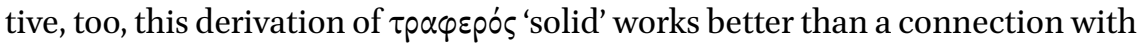

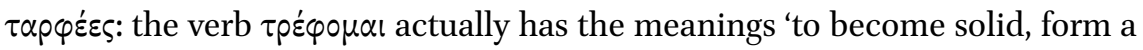

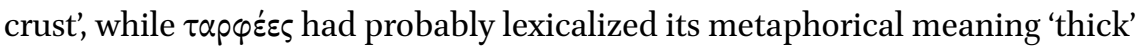
$>$ 'frequent, in large numbers' early on (before the vocalization of " ${ }^{*}$ ).

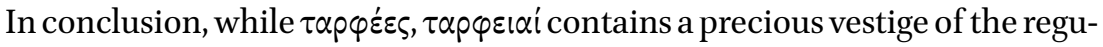

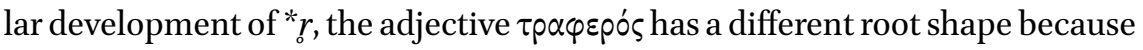

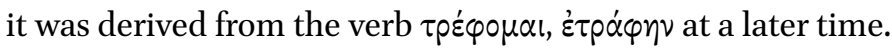

\subsubsection{Analogical Root Vocalism in the Structure * CraCu-}

If $\tau \alpha \rho \varphi \varepsilon$ $\varepsilon \varsigma$ provides compelling evidence for ${ }^{*} r>\alpha \rho$, we are left with the other $u$ -

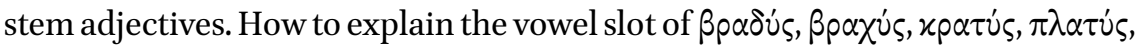

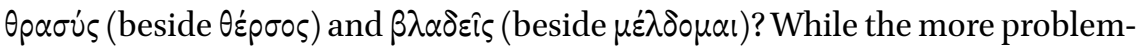
atic cases $\theta p \alpha \sigma u ́ \varsigma$ and $\beta \lambda \alpha \delta \varepsilon i \varsigma$ will be dealt with later, the vocalization in $\beta p \alpha \delta \dot{\zeta}$, $\beta p \alpha \chi \dot{v} \varsigma, x p \alpha \tau \dot{v} \varsigma$, and $\pi \lambda \alpha \tau \dot{s} \varsigma$ can be analogical after full grade forms. Before discussing the evidence for these forms and their cognates, let us pause and ask in which ways such analogical influence may have taken place. 
As we have seen above, there is some evidence for the reconstruction of proterodynamic root ablaut in PIE $u$-stem adjectives. The retention of $-\sigma$ - in $\delta \alpha \sigma v^{\prime}$ gives reason to assume that this ablaut remained intact as late as Proto-Greek. In Van Beek 2013, I assumed that it was even preserved as late as Proto-Ionic,

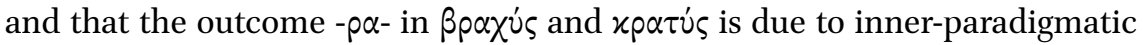
levelling of the vowel slot (" ${ }^{*} \operatorname{rrk}^{h} e u->{ }^{*} m r a k^{h} e u$ - after ${ }^{*} m r e k^{h} u$-). While this assumption gives us some leeway in explaining the vocalized zero grades, it is a rather costly assumption in the absence of further positive evidence, and especially when viewed against the general trend in Greek to eliminate

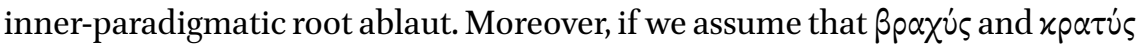
underwent reshaping, we also have to explain why $\theta p \alpha \sigma \dot{\nu} \varsigma$ and $\beta \lambda \alpha \delta \varepsilon i \hat{\varsigma}$ escaped this alleged influence of the strong stem.

As an alternative, one could assume that the full grade root attested in other formations (e.g. the neuter abstract) influenced the vocalization of the adjec-

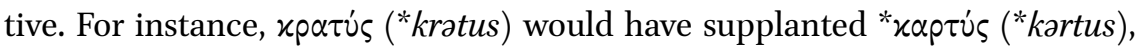
with the regular vowel slot, under the influence of $x p \varepsilon$ ż However, we must take into account that the root vocalism of the adjective

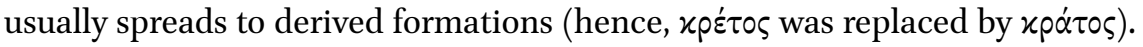

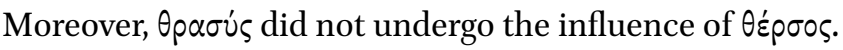

For these reasons, I prefer to ascribe the analogical reshuffling of the root vowel to the forms of comparison. Indeed, most adjectives stand in a close relation with their forms of comparison. ${ }^{83}$ It is straightforward to assume that the adjective ${ }^{*} m r k^{h} u$ - was vocalized as ${ }^{*} m r \partial k^{h} u$ - rather than ${ }^{*} m ə r k^{h} u$ - because

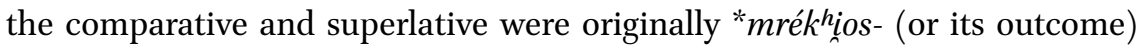

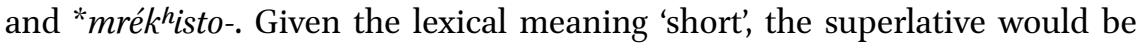
frequent enough to exert such influence. In the case of ${ }^{*} \mathrm{krtu}$ - there is actual evidence that the comparative and superlative retained the original root shape *kret-longer ( $x \rho \varepsilon ́ \sigma \sigma \omega \nu, x p \alpha ́ \tau \imath \sigma \tau о \varsigma<<~ * k r e ́ t i s t o s$; see chapter 5 for further discussion).

With this in mind, let us now discuss in more detail the development of several individual adjectives in -v́s, together with their cognate formations.

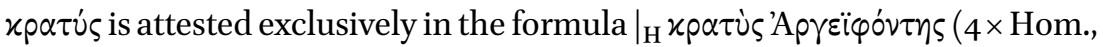
$5 \times$. Herm.), which refers to Hermes. Its meaning is therefore somewhat uncer-

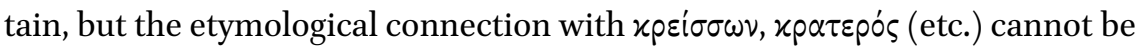
doubted. The reflex - $\rho \alpha$ - may have been influenced by the comparative $x p \varepsilon ́ \sigma-$

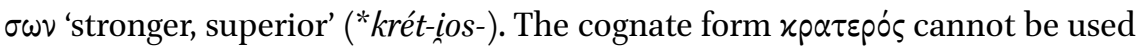

83 Whether the relation between the forms of comparison and the basic adjective is seen as inflectional or derivational is a theoretical issue that need not detain us here. 


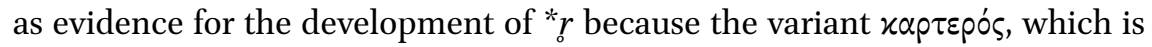
also the Ionic-Attic prose form, displays the regular reflex. This means that $x p \alpha-$

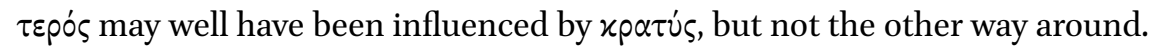
More extensive argumentation and discussion of these claims will be provided in chapter 5 ; for the reflex - $\rho \alpha$ - in Homeric $x p \alpha \tau \alpha i o ́ s, x p \alpha \tau \alpha l-$, see also section 6.8.3.

Bpaxús is the normal word for 'short' (of time) in Classical Greek, but it is unattested in Homer. ${ }^{84}$ The adjective is first attested in its Aeolic form as an adverb $\beta p o ́ x \varepsilon \alpha$ n.pl. (Sappho fr. 31.7), ${ }^{85}$ and from Pindar onwards in its IonicAttic and West Greek form. The primary superlative $\beta p \alpha ́ \chi l \sigma \tau ం \varsigma$ is attested a number of times in poetry, but in classical prose the forms of comparison have

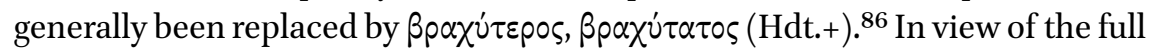
grade in Lat. brevis 'short', the PIE root was * $m r e g^{h_{-} .87}$ As just explained, it is a distinct possibility that a zero grade PGr. ${ }^{*} m_{0} k^{h}$ - $u$ - adapted its vocalization to the root shape ${ }^{*} m r e k^{h}$ - to be reconstructed for the forms of comparison. In Aeolic, $\beta$ pox $-<m r o k^{h}$ - has the regular dialectal reflex; note that names like Thess. Mpoxō (SEG 24: 406.1, ca. 46о-45о вСЕ) prove that initial $\mu \rho-$ was preserved until a relatively late date..$^{88}$

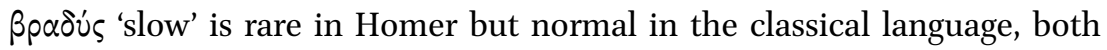
in Attic prose and in poetry. ${ }^{89}$ Primary forms of comparison are only marginally attested. The comparative $\beta p \alpha ́ \delta \delta$ ov (Hes. $O p .5^{28}$ ) is probably analogical, because in an inherited form one would expect to find $-\zeta-<{ }^{*}$-di- after a

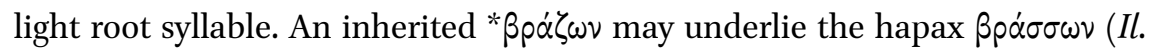
10.226), if this form acquired its $-\sigma \sigma$ - from the antonym $\theta \dot{\alpha} \sigma \sigma \omega \nu$ 'faster.' ${ }^{90}$ The

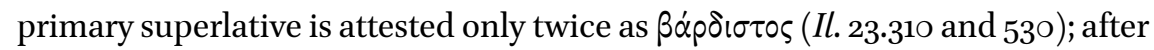

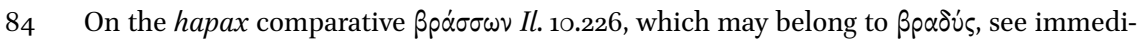
ately below. It seems that $(\sigma) \mu i x p o$ s 'short', bi $\lambda$ ' $\gamma \circ \varsigma$ 'small', and the adverb $\mu$ ivvv $\theta \alpha$ 'for a short time' are used instead of $\beta p \alpha \chi ن ́ \varsigma$ in Epic Greek. This may be due to a general preference for using thematic forms in hexameter Greek (see section 4.2.2); besides, the superlative

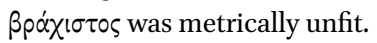

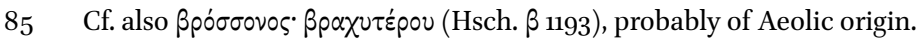

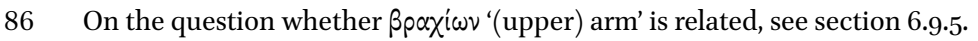

87 A reflex of the zero grade root is found in Ved. múhur 'instantly', Av. mərəzu-jiti- 'shortlived', OHG murg(i) 'short', Goth. gamaurgjan 'to shorten' (denom. verb).

88 For this point, see further section 7.2.1.

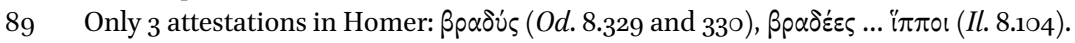

90 Cf. Seiler (1950: 43 and 56f.); differently Barber (2013: 160 with n. 23). The text at $I l .10 .226$

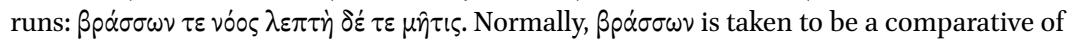
$\beta p \alpha \chi ن$ ऽ 'short' on phonological grounds, but semantically $\beta p \alpha \delta$ v́ would fit much better (cf. Nordheider, $L f g r E$ s.v. $\beta p \alpha ́ \sigma \sigma \omega \nu)$. 


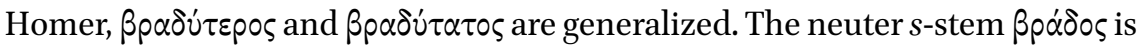
a nonce formation based on $\tau \dot{\alpha} \chi \chi \varsigma \varsigma$, and can be left aside for purposes of reconstruction. ${ }^{91}$

Since $\beta$ padús may refer both to physical slowness (in running or racing) and to lack of mental alertness, it probably has a cognate in Baltic: Lith. gurdùs 'weak, slow, uncommunicative', Latv. gur̃ ds 'tired, weary', both from " $g^{w}{ }^{w} d-u^{-}-{ }^{92}$ The reconstructed form is peculiar because it violates the constraint that a single PIE root may not contain two mediae. Nevertheless, given the perfect formal and semantic match between Greek and Baltic and the relic status of $u$-stem adjectives in Greek, it cannot be doubted that the form is inherited. ${ }^{93}$ Moreover, since no other adjective denoting physical slowness can be reconstructed for PIE (as far as I am able to discern), it seems probable that ${ }^{*}{ }^{{ }^{w}}{ }^{w} d-u^{u}$-fulfilled this function.

In view of its isolation, one could be tempted to take $\beta p \alpha \delta$ ऽ́ as a key example for the regular vocalization of ${ }^{*} r$. It is difficult, however, to establish the original full grade slot of the root. In Proto-Ionic, a full grade may have been around

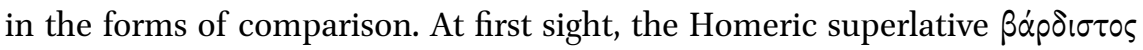

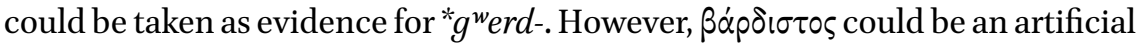

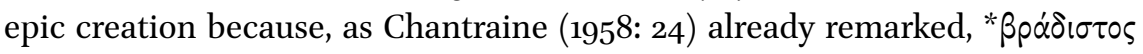
"ne pouvait entrer à aucune place du vers homérique". While metrical utility alone was not a sufficient reason to substitute $\alpha$ for $\rho \alpha$ (see section 4.2.3

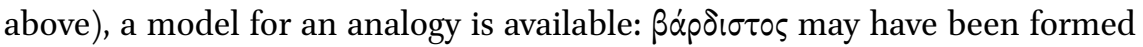

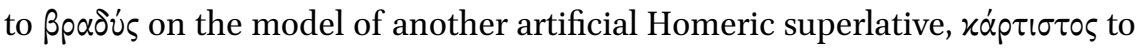
xpatús. This idea receives support from the fact that both roots are used in the context of horse-racing: xáptos denotes the stamina or endurance of horses in

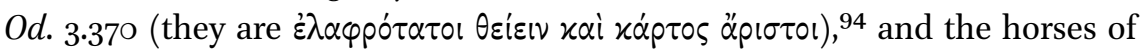

91 Cf. Lamberterie (1989) and Meissner (2006: 102-103).

92 Perhaps, Slavic * ${ }^{*} z r d z$ (> Ru. górdyj 'proud, haughty') is related to the Baltic forms: the $o$-stem may replace an earlier $u$-stem. A thematic noun would be presupposed by Lat. gurdus 'blockhead', but its appurtenance is not certain (cf. Lamberterie 1990: 594-595). For further literature on these etymologies, see NIL 195-196.

93 One may compare the situation with that of PIE $* b$, for which there is hardly any evidence and where the reduction of certain clusters may perhaps explain the occurrence of ${ }^{*} b$ in initial position, as Sasha Lubotsky has suggested in unpublished conference papers. Although we do not know what actually happened in the prehistory of * $g^{*}$ red-, I would not exclude a similar reduction of an initial cluster in this case. There is, therefore, no reason to doubt the Indo-European pedigree of this root.

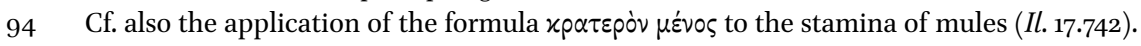
For further connections of the root $x p \alpha \tau$ - with horse-riding, see chapter 5 . 


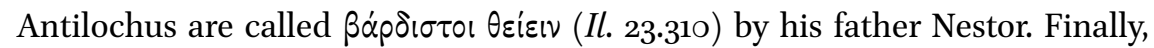
if $\beta p \alpha \dot{\sigma} \sigma \omega \omega$ indeed replaced ${ }^{*} \beta p \alpha \dot{\zeta} \omega \omega \nu$, this form probably recovers an earlier ${ }^{*} g^{w}$ red-ios- .95

As for the abstract $\beta p \alpha \delta$ vin's (Hom.+), its accented suffix only occurs in four

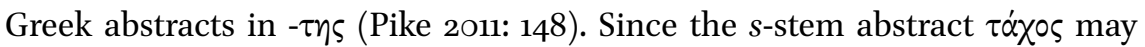

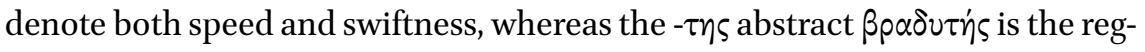

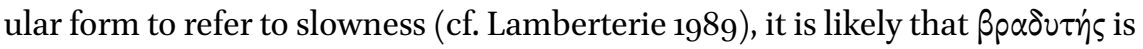

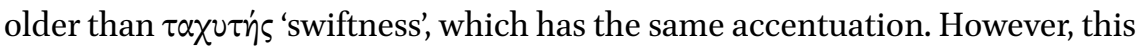

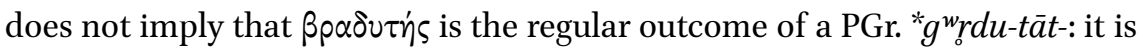
possible that the form was secondarily re-derived from (or influenced by) its base form $\beta p \alpha \delta$ śs.

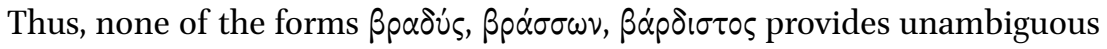
evidence for the regular vocalization of ${ }^{*} r$, because the original full grade slot of the root is not known with certainty. If this was ${ }^{*} g^{w} r e d-$, it may have influenced the outcome of * $g^{w} r d-u_{0}$-.

The adjective $\pi \lambda \alpha \tau \dot{ }$ ऽ 'broad, extended; flat' is cited as a prime example of the development of the syllabic liquids in most manuals. ${ }^{96}$ It is well-attested from Homer onwards, and also attested in Lesbian poetry ( $\pi \lambda \dot{\alpha} \tau v$, Alc. fr. 74). The forms of comparison were secondarily rebuilt as $\pi \lambda \alpha \tau \dot{\tau} \tau \varepsilon p o \varsigma,-\tau \alpha \tau \circ \varsigma$. Related forms attested in Greek are $\pi \lambda \alpha \tau \alpha \mu \omega$ ' 'flat stone or rock' (h. Hom. + ), $\pi \lambda \alpha \dot{\tau} \tau o \varsigma$ 'breadth, width; plane surface' (Cypr. fr. 1.2, Simon., Hdt.+), and adjectives in $-\pi \lambda \alpha \tau \eta^{\prime} \varsigma$ (X., Th., Arist.). As will be discussed in chapter 10, $-\lambda \alpha$ - may well be the regular reflex of $*$, but in $\pi \lambda \alpha \tau \dot{v}$ s it could also be explained in the same way as in $x p \alpha \tau \dot{v} \varsigma$ and $\beta p \alpha \chi \dot{v} \varsigma$, i.e. as an adaptation to the original full grade slot (PIE ${ }^{*}$ pleth $\left.2^{-}\right) .{ }^{97}$ Though no reflex of this full grade is attested in Greek, it may have been eliminated in the $s$-stem noun at a relatively recent date. Outside of Greek, the same formation is attested in Ved. práthas-, Av. fraきah- 'breadth', and OIr. leth 'side'; cf. also the primary verb Ved. práthate 'extends'.

95 I assume that the comparative $\beta \alpha p \delta$ v́ $\varepsilon \rho \circ \varsigma$, attested in Theocritus, is also an artificial poetic creation.

96 It is possible that $\pi \lambda \alpha \tau \dot{\jmath} \varsigma$ 'brackish' is a different adjective, both synchronically and historically: see Lamberterie (1990: 452-463). Proponents of the historical identity of both lexemes believe that $\pi \lambda \alpha \tau \dot{ }$ ' 'broad', as an epithet of the Hellespont, was misunderstood to mean 'salty', an important argument being that Herodotus also calls the Hellespont $\dot{\alpha} \lambda \mu v$ pós 'salty'. Cf. GEW s.v. $\pi \lambda \alpha \tau \dot{\zeta} \varsigma$ 2. and Mayrhofer EWAia s.v. pațu- (both embracing this view), $D E L G$ s.v. $2 \pi \lambda \alpha \tau \dot{\varsigma} \varsigma$ (doubting it). Against this, Lamberterie remarks that $\pi \lambda \alpha \tau \dot{\zeta} \varsigma$ only denotes brackish, never salty water.

97 According to Blanc (2012), this full grade is reflected in $\alpha$ ' $\pi \lambda \varepsilon \tau \circ \varsigma$ 'immense', which would have arisen from *sm-pleth ${ }_{2}$-eto- by haplology. 
In sum, the forms $\beta p \alpha \delta \dot{v} \varsigma, \beta p \alpha \chi u ́ s, x p \alpha \tau \dot{v} \varsigma$, and $\pi \lambda \alpha \tau u ́ \varsigma$ can no longer be viewed as compelling evidence for the regular reflex of the syllabic liquid. ${ }^{98}$ The forms $\theta p \alpha \sigma \dot{ } \varsigma$ and $\beta \lambda \alpha \delta \varepsilon i \varsigma$, on the other hand, constitute serious evidence for - $\rho \alpha$ - and $-\lambda \alpha$ - as the regular vocalizations of the respective syllabic liquids: they cannot have been influenced by cognate full grade forms. There is, however, also evidence for a different reflex of the zero grade: the factitive verbs $\alpha \mu \alpha \lambda \delta \delta v \omega$ 'to erode, weaken' and $\theta \alpha \rho \sigma \dot{v} v \omega$ 'to encourage'. As we have seen, verbs in - $v v \omega$ were productively derived only from $u$-stem adjectives until a relatively recent date (section 4.2.3). Therefore, $\alpha \mu \alpha \lambda \delta \dot{v} v \omega$ and $\theta \alpha \rho \sigma \dot{v} v \omega$ seem to imply the earlier existence of adjectives * ${ }^{*}(\grave{\alpha}) \mu \alpha \lambda \delta \dot{\alpha} \varsigma$ and ${ }^{*} \theta \alpha \rho \sigma \dot{\varsigma} \varsigma$. We have to account for the coexistence of both vocalizations.

\section{4 * * $\beta \lambda \alpha \delta \delta$ ऽ versus $\alpha \mu \alpha \lambda \delta \dot{v} v \omega$}

Traces of the zero grade reflex $\beta \lambda \alpha \delta-<{ }^{*} m_{0} d$ - are attested only in glosses (Hsch., $\beta 54-59)$ :

- $\beta \lambda \alpha \delta \dot{\alpha} \cdot \alpha \omega \omega \rho \alpha, \mu \omega \rho \alpha$ AS.99 $\omega \mu \alpha \dot{\alpha}$ ('untimely; dull, stupid'; 'raw, uncooked')

- $\beta \lambda \alpha \dot{\alpha} \alpha \nu \cdot v \omega \theta \rho \omega \varsigma$ ('slothful')

- $\beta \lambda \alpha \delta \alpha \rho \alpha \dot{\alpha} \omega \omega \rho \alpha$ AS. $\mu \omega \rho \alpha \dot{\alpha} . \dot{\omega} \mu \alpha \dot{\alpha}$ AS

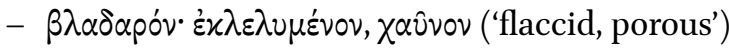

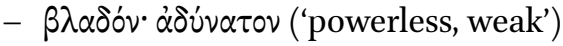

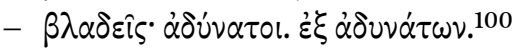

Thus, an adjective $\beta \lambda \alpha \delta$ ú is only attested in the plural form $\beta \lambda \alpha \delta \varepsilon i \varsigma{ }^{101}$ The appurtenance of the first three glosses is not straightforward: $\omega \mu o$ ' 'raw' means

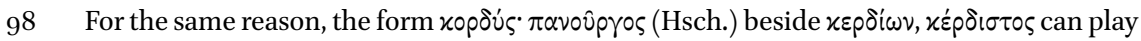

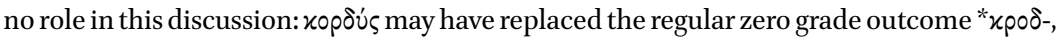
in an Aeolic dialect, under the influence of an older strong stem * $\varkappa \varepsilon p \delta \dot{\iota} \varsigma$. Theoretically, however, 火opoú

99 Words provided with these sigla may have been incorporated later into the text of Hesychius from the lexicon of Cyrillus of Alexandria (5th c.); A and S denote two manuscripts of that lexicon. See Cunningham (2018: $\mathrm{x})$.

100 The alphabetical order of these glosses ( $\beta \lambda \alpha \delta \varepsilon \hat{\imath} \varsigma$ following $\beta \lambda \alpha \delta$ óv) may confirm that $\beta \lambda \alpha-$

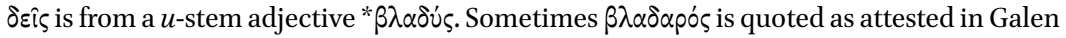
(e.g. Rau 20og: 153), but there the form is actually a conjecture for transmitted $\beta \lambda \alpha \beta \varepsilon p \alpha i$

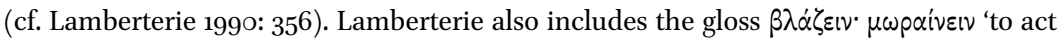
foolishly', but its appurtenance to * $\beta \lambda \alpha \delta$ ú seems uncertain to me.

101 It has been suggested that $\beta \lambda \alpha \delta \delta^{\circ} \cdot \alpha \dot{\delta} v \alpha \alpha \tau \nu$ should be corrected to $\beta \lambda \alpha \delta \dot{v} v(G E W, D E L G$ ), but this is rejected by Lamberterie (1990: $356 \mathrm{n}$. 4), who also convincingly argues against the necessity to restitute $\beta \lambda \alpha \delta$ ú for the transmitted form $\beta p \alpha \delta$ ¿́ at Hp. Aër. 20 (o.c. $35^{6-}$ $\left.35^{8}\right)$. 
almost the opposite of 'weak, soft', and the meanings contained in the glosses $\alpha \omega \omega \rho \alpha, \mu \omega \rho \alpha$ and $\nu \omega \theta p \omega \varsigma$ could have developed from 'weak', but this is not evi-

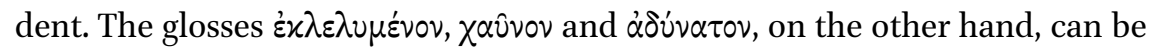
understood quite well as having developed from 'weak, soft'.

The verb $\alpha \mu \alpha \lambda \delta \dot{v} v \omega$ is attested from Homer onwards, but in various different meanings. The philological evidence for this verb has been extensively discussed by Lamberterie (1990). From his discussion, I retain the following conclusions:

(1) In Homer, $\alpha \mu \alpha \lambda \delta$ v́v $\omega$ occurs three times in a similar context. On each occasion, the Achaean wall is reduced to dust, corroded, by the erosion of wind and water. The meaning 'to make invisible', found in post-Homeric poetry, is ultimately based on reinterpretations of the Homeric passages. In the Hippocratic Corpus, $\alpha \mu \alpha \lambda \delta \mho v v \omega$ means 'to weaken' (vel sim.); sometimes, $\alpha \mu \alpha \lambda \delta \dot{v} v \omega$ is even used as an equivalent of $\alpha \mu \beta \lambda \dot{v} v \omega$ 'to make blunt' (cf. Lamberterie 1990: $364-368$ ).

(2) The $\dot{\alpha}$ - of $\dot{\alpha} \mu \alpha \lambda \delta \delta v \omega$ may be due to contamination with $\dot{\alpha} \mu \alpha \theta \dot{v} v \omega$ 'reduce to sand' (Hom.+), which may itself owe its factitive suffix - $v v-$ to $\alpha \mu \alpha \lambda \delta \delta v \omega$ (cf. Lamberterie 1990: 363$){ }^{102}$ It is noteworthy that the $\dot{\alpha}$ - of the gloss $\dot{\alpha} \mu \varepsilon \dot{\varepsilon} \lambda \delta \varepsilon v$.

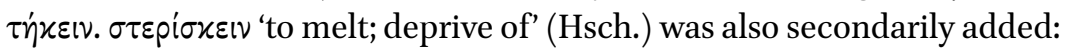
cf. $\mu$ '̇ $\lambda \delta \circ \mu \alpha$ ' 'to become soft by boiling or heating' (Il. 21.363, Nic.), from the same root as $\dot{\alpha} \mu \alpha \lambda \delta \dot{v} v \omega .^{103}$

(3) As Lamberterie (1990: 372-373) shows, the PIE root was * meld-rather than

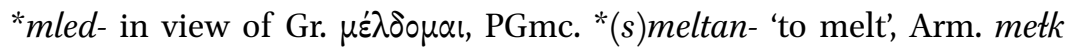
'soft' < *meldui-.104 The full grade of Ved. vímradā (RV, hapax) and úrnamradas- 'soft like wool' is an innovation of Indo-Aryan. ${ }^{105}$

102 I would add to this that other adjectives like $\dot{\alpha} \mu \alpha \lambda$ ó 'weak' (Il.+, no etymology), $\dot{\alpha} \pi \alpha-$ $\lambda$ ós 'soft, tender' (Hom.+), à $\mu$ avpós 'dark, unseen, invisible' may have played a part in the reshaping of an earlier * $\mu \alpha \lambda \delta \dot{v} v \omega$. Lamberterie (1990: 362) also draws attention to the gloss $\alpha \beta \lambda \alpha \delta \delta^{\prime} \omega \varsigma \cdot \eta^{\prime} \delta \varepsilon^{\prime} \omega \varsigma^{\prime}$ 'in a pleasant way, agreeably' (Hsch.). The meaning of the gloss may derive from 'soft', in which case the addition of $\dot{\alpha}$ - would have to be secondary (as with $\dot{\alpha} \mu \alpha \lambda \delta \dot{v} v \omega$ ). For semantic reasons this seems preferable over assuming a privative $s$-stem compound *n-mld-es-; besides, a zero grade root would be unexpected as a second compound member.

103 The second gloss $\sigma \tau \varepsilon p i \sigma \kappa \varepsilon i \nu$ suggests that the glossator was confused by the similarity with $\alpha \mu \varepsilon \dot{\rho} \delta \omega$ 'to deprive (of eyesight)'.

104 Armenian metk confirms that the root did not have an initial laryngeal. Unclear to me is the claim of Hamp (1988: 89) that Arm. metk is a "revocalization" of *matk.

105 Within early Vedic, the root mrad 'to soften' is semantically distinct from mard 'to crush', even if both roots were confused early on (Mayrhofer EWAia s.v. MRAD). Mayrhofer reconstructs PIE * $\left(h_{2}\right)$ mled- 'to become weak, dissolve' as against *merd $(H)$ - "zerdrücken, zerreiben" (comparing this with Lat. mordeō 'to bite'). However, it would not be wise to base 
(4) $\alpha \mu \alpha \lambda \delta \delta v \omega$ presupposes the earlier existence of an adjectival stem *( $(\dot{\alpha}) \mu \alpha \lambda \delta$ '́ 'reduced to dust' (Lamberterie 1990: 364 ).

A semantic problem must now be taken into consideration. All reflexes of the adjective PIE * $m_{o} l d-u$ - carry the meaning 'weak, soft, tender', but $\alpha \mu \alpha \lambda$ $\delta \dot{v} v \omega$ means 'to corrode'. At first sight, then, the meaning of $\alpha \mu \alpha \lambda \delta \dot{v} v \omega$ seems to match that of Vedic mard 'to crush', which is both etymologically and synchronically distinct from the root $\mathrm{mrad}$ 'soften'. Lamberterie answers this problem by assuming that the meaning 'to reduce to dust' displayed by the Homeric factitive is old, claiming that it "reflète directement le sens fondamental de la racine "mel $\left(H_{2}\right)$ - 'broyer, moudre' (...)" (1990: 364$)$. This forces him to consider the meaning 'weak, soft, tender', attested in all branches that have a reflex of the $u$ stem adjective, as a secondary development from 'crushed, pulverized'. It does not seem very likely, however, that this semantic development took place independently in various different branches. Although it is possible that the roots * $m e l d$ - and ${ }^{*} m e l h_{1}$ - were identical at a pre-stage of PIE (via the 'effet Kortlandt'), the meaning of * meld- 'to become weak or soft' was clearly distinct from that of * melh $_{1}$ - 'to crush' in PIE itself. ${ }^{106}$ We may assume that the meaning of * $(\dot{\alpha}) \mu \alpha \lambda$ -

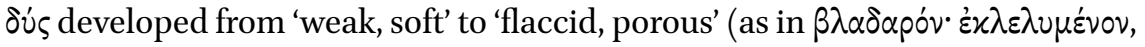
$\chi \alpha \hat{v} v o v$ Hsch. discussed above);107 and from * $(\dot{\alpha}) \mu \alpha \lambda \delta \dot{\varsigma} \varsigma$ the factitive verb $\alpha \mu \alpha \lambda$ -

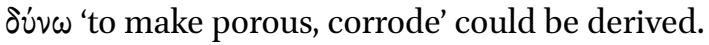

It remains to explain the different vocalizations in * $(\dot{\alpha}) \mu \alpha \lambda \delta \dot{\delta}$ - and $* \beta \lambda \alpha \delta \dot{\delta} \varsigma$. It would not help to start from an adjective *méld-u-, *mld-éu- with root ablaut, for it would be difficult to derive both ${ }^{*} \mu \alpha \lambda \delta$ - and ${ }^{*} \beta \lambda \alpha \delta$ - from it within the same dialect. ${ }^{108}$ Moreover, it is uncertain whether root ablaut was preserved in adjectives in -v́s until the vocalization of * $l$.

As a way out of this dilemma, one might surmise that the forms with $\beta \lambda \alpha \delta$ are not from Ionic-Attic, but from a different dialect. The glosses provide no

the reconstruction * $\left(h_{2}\right)$ mled- solely on the Indo-Aryan evidence, because this branch lost not only the difference between $l$ and $r$, but also has no reflexes of word-initial preconsonantal laryngeals. As a result, the full grade slot could become a useful means to distinguish between two roots that had merged as a result of regular sound change. In this case, the roots * meld- 'to become weak' ( Lat. mollis) and * $h_{2} m e r d$ - 'to crush, bite' ( Lat. mordeō) could be kept apart by the creation of a novel full grade in mrad 'to soften', once full-grade forms deriving from * meld- had been lost.

106 Cf. $L I V^{2}$, "meld- 'weich werden' versus * melh $_{2}$ - 'zerreiben, mahlen'. I reconstruct the latter root as *melh ${ }_{1}$ - on account of Myc. me-re-ti-ri-ja 'female corn grinders', among other reasons.

107 Note that German weich may mean both 'weak, soft' and 'flaccid'.

108 After *mldéu- > *mladéu-, one would expect an analogical reshaping either to (1) *méldu-, "maldéu- and hence levelling to *maldú-, *maldéu-, or directly to (2) *mladús, *mladéu-. Neither scenario can explain $\beta \lambda \alpha \delta \dot{\nu} \varsigma$ and $\alpha \mu \alpha \lambda \delta \dot{v}$ - at the same time. 
clue about their provenance, but since lexical meanings such as 'flabby' and 'porous' would be compatible with medical terminology, one could hypothesize that forms with $\beta \lambda \alpha \delta$ - are from the Hippocratic Corpus (a considerable number of treatises belonging to this corpus are known to have been lost). In that case, it may be wondered whether these forms could be of Doric origin: Hippocrates and his pupils lived and worked on the island of Cos. This speculation may receive some support from the adjective $\pi \lambda \alpha \delta \alpha$ pós: one of its meanings is 'flaccid', which is also how $\beta \lambda \alpha \delta \alpha \alpha$ ós is glossed, and $\pi \lambda \alpha \delta \alpha \rho o ́ s$ is mainly attested in the Hippocratic corpus. It is not unthinkable that $\pi \lambda \alpha \delta \alpha-$ pós is a secondary reshaping of $\beta \lambda \alpha \delta \alpha p o ́ s$ in Ionic, perhaps under the influence of $\pi \lambda \alpha \dot{\sigma} \sigma \sigma \omega$ 'to knead'. In this case, $\beta \lambda \alpha \delta \alpha$ pós could well stem from a different dialect, and the same might then hold for $\beta \lambda \alpha \delta$ ú

In conclusion, the adjective * $(\dot{\alpha}) \mu \alpha \lambda \delta$ í $\varsigma$ that seems to be presupposed by the factitive verb $\alpha \mu \alpha \lambda \delta \dot{v} v \omega$ 'to corrode' would be the expected Ionic-Attic continuant of PIE * $m$ ld -ú- 'weak, flaccid', provided that its vocalization was influenced by the full grade (as found e.g. in the forms of comparison and the primary verb $\mu \dot{\varepsilon} \lambda \delta \delta \mu \alpha \mathrm{l})$. On the other hand, in glosses with $\beta \lambda \alpha \delta$ - we find a direct reflex of * ${ }^{*}$. The main problem is posed by the gloss $\beta \lambda \alpha \delta \varepsilon i \varsigma$, which seems to be the plural of an adjective $\beta \lambda \alpha \delta$ ís: why did this form coexist with ${ }^{*}(\dot{\alpha}) \mu \alpha \lambda \delta \dot{\varphi} \varsigma$ ? There is no obvious explanation, but it is conceivable that one of these forms is of nonIonic-Attic origin. In any case, $\beta \lambda \alpha \delta$ - reflects a zero grade * $m_{0} l d$-; this conclusion will be bolstered with further arguments in chapter 10.

\section{5 $\quad \theta \rho \alpha \sigma \dot{\varsigma}$ versus $\theta \alpha \rho \sigma u ́ v \omega$}

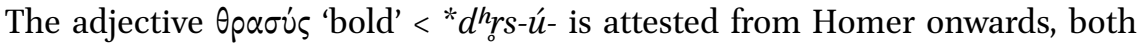
in poetry and in prose. Given that the root had a full grade $\theta \varepsilon \rho \sigma-$, it seems a strong counterexample against ${ }^{*} r>-\alpha \rho$ - as the regular Ionic-Attic development. However, $\theta p a \sigma u ́ s$ is different from other $u$-stem adjectives with a similar root structure in that its zero grade reflex does not show the influence of the original

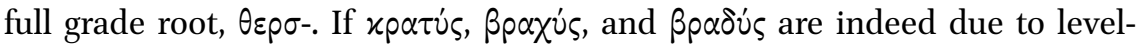
ing, one would expect * $d^{h}{ }_{r} s-u$ - to end up as $\theta \alpha p \sigma \dot{s} \varsigma^{*}$ under influence of * $d^{h}$ ers-. Although some historical grammars cite a form $\theta \alpha \rho \sigma v^{\prime},{ }^{109}$ it is not attested as an appellative, nor as a simplex, but only as a first compound member $\Theta \alpha \rho \sigma v-$, $\Theta$ $\mathrm{pppv-in} \mathrm{personal} \mathrm{names;} \mathrm{moreover,} \mathrm{these} \mathrm{names} \mathrm{occur} \mathrm{in} \mathrm{West} \mathrm{Greek} \mathrm{dialects,}$

109 Lejeune (1972), Sihler (1995); Chantraine's reference to a "Oapoús (attesté en composition)" (DELG s.v. $\theta \dot{\alpha} \rho \sigma \circ \varsigma)$ is more precise but may still give rise to confusion. 
not in Ionic-Attic. ${ }^{110}$ A key question is whether an adjective * ${ }^{*}$ ap oús indeed existed at some pre-stage of Ionic-Attic.

In the following pages I will therefore consider all derivatives of this root, first in Homer, then in Classical Attic and Ionic. The semantic values of the attested formations play a key role: they may help us establish the historical and synchronic derivational relationships.

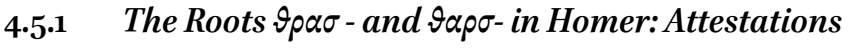

Table 4 (next page) contains all forms containing the root shapes $\theta p \alpha \sigma$ - and $\theta \alpha p \sigma-$ as attested in Homeric Greek.

It appears that there are no true doublets in Homer. The only exception is the neuter abstract $\theta \dot{\alpha} \rho \sigma o \varsigma \sim \theta \rho \dot{\alpha} \sigma 0 \varsigma$, but the variant $\theta \rho \dot{\alpha} \sigma 0 \varsigma$ may well be a one-off

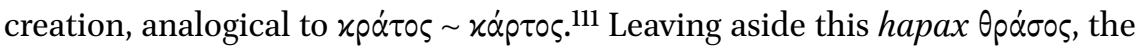
root shape $\theta \rho \alpha \sigma$ - only occurs in $\theta p \alpha \sigma \dot{\varsigma} \varsigma$ and compounds with $\theta p \alpha \sigma v-$, for which no variant with $\theta \alpha \rho \sigma-$ exists. It is therefore not true that - $\alpha \rho$ - could always be substituted for - $\rho \alpha$ - in Homer, or vice versa (pace Lamberterie 1990: 849 and $852)$.

The allomorph $\theta \alpha \rho \sigma$-can be due to the secondary introduction of $a$-vocalism in a pre-form with * $\theta \varepsilon p \sigma$-. Thus, the full grade root of $\theta \varepsilon \dot{p} \rho \sigma \varsigma$, attested in Alcaeus, has been replaced by $\theta \dot{\alpha} \rho \sigma o \zeta$ in Ionic-Attic. Similarly, in $\pi 0 \lambda \nu \theta \alpha \rho \sigma \eta \dot{s}$ the second member replaces $-\theta \varepsilon \rho \sigma \eta \dot{s}$, which is preserved in Homer only in the personal

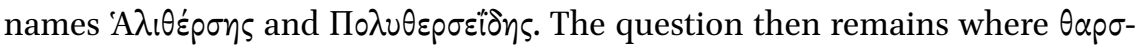
originated: does it also reflect an older zero grade in some forms, whether by regular sound change or analogical reshaping?

In the first member of compounds (including personal names), the two variants available in poetry were $\theta p a \sigma v-$ and $\theta \varepsilon p \sigma t-$. They serve as counterparts of both $\theta p \alpha \sigma u ́ \varsigma$ and $\theta \alpha \rho \sigma \alpha \lambda \varepsilon \dot{\varepsilon} \circ$, , $\theta \dot{\alpha} \rho \sigma o \varsigma$. While $\theta \varepsilon p \sigma \mathrm{l}$ is a clear archaism, it seems as if $\theta$ parv- may have been introduced in compounds at any time. However, since the distinction between these first members was utilized for metrical variation, and since both $\theta \varepsilon p \sigma l-$ and the reflex of ${ }^{*} t^{h_{r}} r u$ - are widespread in epigraphic onomastic material, ${ }_{112}^{12}$ the coexistence of $\theta \varepsilon \rho \sigma \mathrm{l}-$ and $\theta \rho \alpha \sigma \nu$ - (earlier ${ }^{*} t^{h} r s u$-) is bound to be old as well.

\footnotetext{
110 I regard the interpretation of the Mycenaean man's name $t a-s u$ as uncertain.

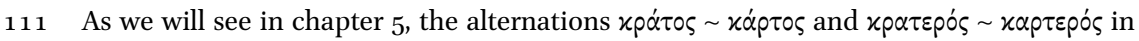
Epic Greek are structural and have a real linguistic basis.

112 In epigraphic onomastic material we also encounter a variant $\Theta \alpha \rho \sigma \nu$ - or $\Theta \alpha p \rho v-$, especially on Crete and in archaic Theran graffiti. In these dialects these forms may well regularly reflect ${ }^{*} t_{r}{ }_{r} s u$-, but in other dialects it is difficult to exclude that $\Theta \alpha p \sigma v-$ replaced $\Theta p \alpha \sigma v-$ under the influence of $\theta \alpha \rho \sigma$ - in related formations such as $\theta \dot{\alpha}$ pбos. Cf. sections 3.1.2
} 
TABLE 4 Forms with the root shapes $\theta \rho \alpha \sigma$ - and $\theta \alpha \rho \sigma$ - in Homer

\begin{tabular}{|c|c|}
\hline$\theta p \alpha \sigma-$ & $\theta \alpha p \sigma-$ \\
\hline \multicolumn{2}{|c|}{ 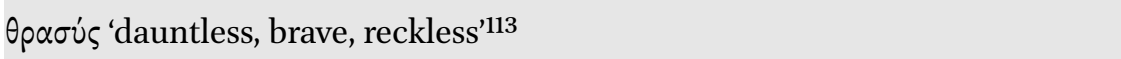 } \\
\hline \multicolumn{2}{|l|}{ 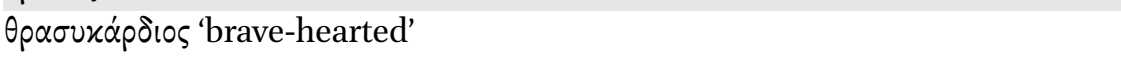 } \\
\hline \multicolumn{2}{|l|}{ 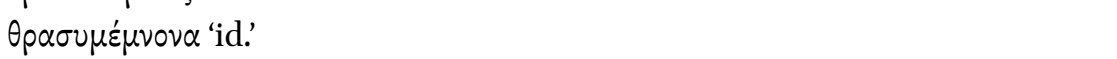 } \\
\hline \multicolumn{2}{|l|}{ 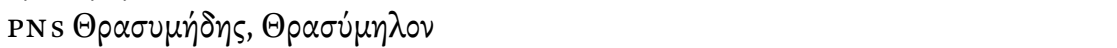 } \\
\hline & $\theta \alpha p \sigma u ́ v \omega$ 'to instill courage' \\
\hline & 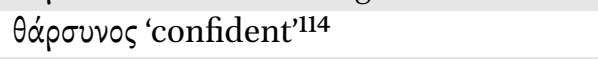 \\
\hline & 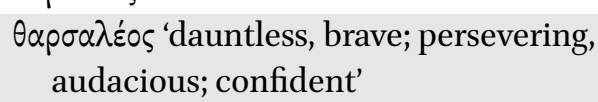 \\
\hline & $\pi 0 \lambda \nu \theta \alpha p \sigma \varsigma^{\prime}$ 'dauntless' \\
\hline \multirow[t]{2}{*}{ 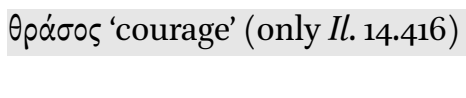 } & Od́poos 'perseverance, stamina; courage' \\
\hline & $\theta \alpha p \sigma \varepsilon \varepsilon^{\prime}$ 'to hold on; gain courage' \\
\hline
\end{tabular}

In sum, leaving aside the hapax $\theta p \alpha \dot{\sigma o s}$, the root allomorph $\theta \rho \alpha \sigma$ - is limited in

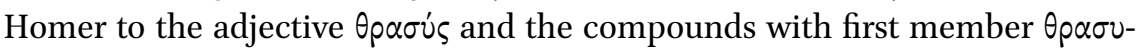
(including personal names). This distribution calls for an explanation. In what follows, I argue that there is evidence for a lost adjective * $\theta \alpha$ poú $\zeta$ in Proto-Ionic, and suggest that $\theta p \alpha \sigma \dot{\varsigma} \varsigma$ reflects an archaism not of the spoken language, but of the epic tradition. Not only is $\theta$ parús morphologically isolated, but it is also semantically detached from most forms with $\theta \alpha p \sigma-$.

and 3.4.3 on names in @opov- attested in Cretan and Arcadian inscriptions, and section 3.4.1 on Cyprian to-ro-su-ta-mo.

113 Forms of comparison of $\theta p \alpha \sigma u ́ \varsigma$ are not attested in early Greek epic. If the Classical forms $\theta p \alpha \sigma \dot{\tau} \tau p \rho \varsigma$ and $\theta p \alpha \sigma u ́ \tau \alpha \tau o \varsigma$ already existed, they could not have been used in epic meter.

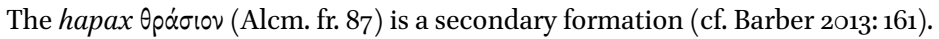

114 Oápouvos 'confident' only occurs twice in Homer. Its derivational morphology is unclear. According to Nussbaum (1976: 76) it is a composite Caland formation, with -no- stacked onto * $d^{h_{0}}$ s- $u$-; older suggestions are listed in Risch (1974: 150-151), with further literature. Since the meaning of $\theta \dot{\alpha}$ povvos matches that of the other $\theta \alpha \rho \sigma$ - forms, and since it only occurs in Homer, I suspect that it was created as a metrical alternative for $\pi$ iouvos 'confident' (Hom.+), the only other adjective in -vvos and one with an almost identical lexical meaning. Since the root meaning 'confidence' of $\theta \alpha \rho \sigma$ - is innovative, it is unwarranted to use $\theta \dot{\alpha}$ ovuvos as evidence for ${ }^{*} r>-\alpha \rho-$. 


\subsubsection{The Roots $९$ p $\sigma$ - and $\vartheta \alpha \rho \sigma-$ in Homer: Semantics}

It is usually thought that there was not yet a tangible semantic or lexical dis-

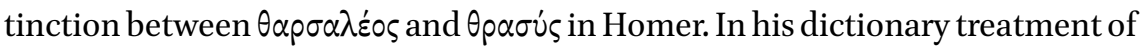

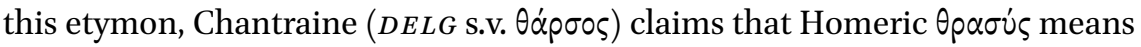
'brave' as an epithet of Hector and other heroes, 'courageous' in the phrase

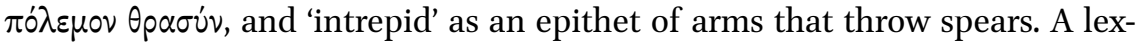
ical split allegedly first occurs in Classical Attic, which (generally speaking)

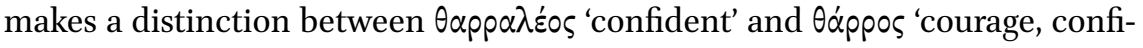

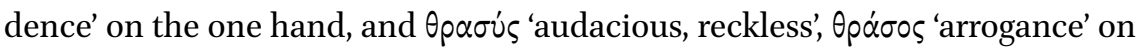
the other. This semantic specialization is thought to be of post-Homeric date and supposed to have developed by the lexicalization of a pragmatic difference between a pejorative sense 'reckless' and a laudatory meaning 'confident, courageous'.115

In reality, the Homeric evidence may point in a different direction. In his extensive discussion of the semantics of this root, Lamberterie (1990: 854) shows that $\theta \alpha p \sigma \alpha \lambda \varepsilon \dot{0}$, not $\theta p \alpha \sigma u ́ s$, serves as the productive adjectival counterpart of $\theta \dot{\alpha} p \sigma o \varsigma, \theta \alpha \rho \sigma \varepsilon \dot{\varepsilon} \omega$, and $\theta \alpha \rho \sigma u ́ v \omega$. He compares the following items of Homeric phraseology:

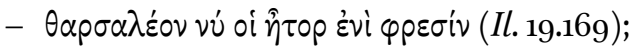

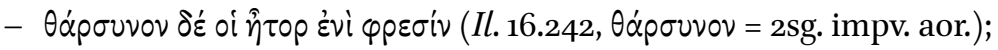

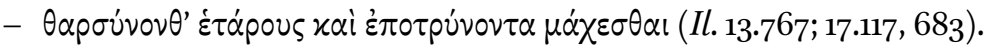

This observation is corroborated by a closer consideration of the two Homeric forms and their semantics. In Homer $\theta \alpha p \sigma \alpha \lambda \varepsilon \dot{\varepsilon} \varsigma$ has the same range of meanings as the abstract noun $\theta \dot{\alpha} \rho \sigma o \varsigma$, from which it was probably derived (cf. section $4 \cdot 3 \cdot 2)$ :

(1) 'persistence' (whether in a positive sense 'stamina', or pejorative 'obstinacy, perseverance, audacity'), cf.

115 In the words of Chantraine (DELG S.v. Өd́poos), "Cette spécialisation est secondaire comme le prouvent les faits homériques et les composés anciens avec $\theta p \alpha \sigma u ́ \varsigma$ au premier membre (...)"; cf. also Lamberterie (1990: 849 and 855-859). Meissner (2006: 71), however, adds a different nuance: "It is important to note that $\theta p \alpha \dot{\sigma o s}$ has the same negative connotation that the basic adjective $\theta p \alpha \sigma u ́ \varsigma$ had developed much earlier. Already in Homer $\theta p \alpha \sigma u ́ \varsigma$ is attested in the meaning 'over-bold', 'rash' (cf. Od. 10.436, where Eurylokhos tries to hold back the companions, warning them against rash Odysseus through whose $\alpha \tau \alpha \sigma \theta \alpha \lambda i \alpha \iota$ many have perished), though $\theta$ parú can, of course, be positive as well." In my view, however, the distinction between positive and negative connotations is epiphenomenal. 


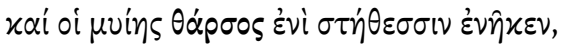

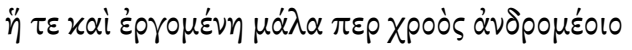

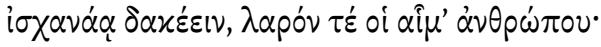

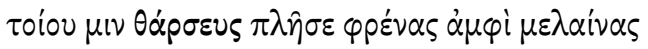

Il. $17 \cdot 570-573$

and she [Athena] put into his [Menelaus] heart the perseverance of a mosquito, which even when brushed off keeps trying to bite in the human skin; it likes the taste of human blood; with a similar endurance did she fill him in his dark lungs.

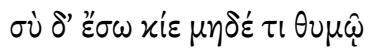

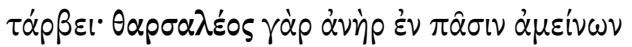
हैp

Od. $7.5^{\circ}-5^{2}$

But do you enter the palace and do not be timid at heart: for a man who perseveres has more success in all matters, even if he comes from somewhere else.

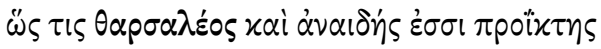

Od. 17.449

such an obstinate and shameless beggar you are

(2) 'courage, confidence', cf.:

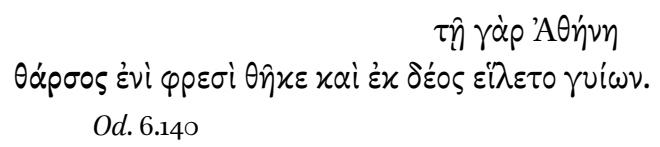

and in her [Nausicaä] heart Athena put courage and she took fear out of her legs.

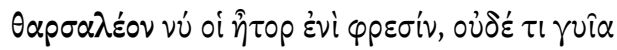

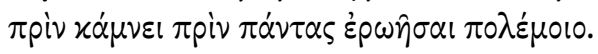

Il. 19.169

The heart in his chest is courageous, and his limbs do not get tired before everyone else has stopped fighting. 
On the other hand, in pre-classical poetry $\theta$ paбús usually means 'bold, intrepid', and this is clearly an older meaning than 'courageous, confident' or 'audacious.'116 However, already in Homer there are restrictions on the use of $\theta p a \sigma u$ s. The positive nuance 'intrepid, dauntless' is retained in compounds and in the archaic formula $\theta p \alpha \sigma \varepsilon ı \dot{\alpha} \omega \nu$ à $\pi \dot{o} \chi \varepsilon ı \rho \omega \nu$, where it qualifies the persevering arms of warriors (that keep throwing spears). The negative nuance 'reckless' is predominant when $\theta$ paбús qualifies human beings: Hector (whose recklessness is thematic throughout the Iliad), his charioteers, and Odysseus in a passage where his foolhardy eagerness to confront the Cyclops is criticized by one of his companions. ${ }^{117}$ Finally, the phrase $\pi \dot{d} \lambda \varepsilon \mu \circ v \theta p \alpha \sigma o v(3 \times)$ is used twice when Helen's abduction is mentioned as the cause of the Trojan war (cf. also Il.10.2728):

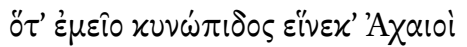

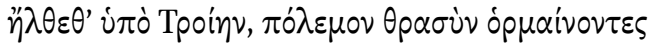

$$
\begin{aligned}
& \text { Od. 4.145-146 }
\end{aligned}
$$

when you Achaeans came to the walls of Troy on account of me, bitchface, waging a stout-hearted/reckless war

Thus, in spite of some potential overlap between $\theta \alpha p \sigma \alpha \lambda \varepsilon \dot{o \zeta}$ and $\theta p \alpha \sigma u ́ \varsigma$ in Homer, there are in fact clear differences between the two in meaning and use. While $\theta p \alpha \sigma u ́ \varsigma$ never means 'confident, courageous', $\theta \alpha \rho \sigma \alpha \lambda \varepsilon$ ś ${ }^{\prime}$ and $\theta \alpha \rho \sigma \dot{v} v \omega$ are readily used in this sense. If the phrase $\theta \alpha \rho \sigma \alpha \lambda \varepsilon \dot{\varepsilon} 0 \nu . . . \hat{\eta} \tau \circ \rho$ is paralleled by

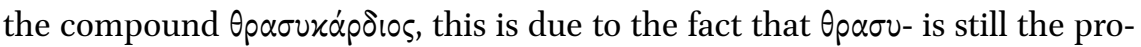
ductive 1st compound member corresponding to $\theta \alpha \rho \sigma \alpha \lambda \varepsilon_{\varepsilon} \circ \zeta$ and $\theta \dot{\alpha} \rho \sigma \circ \varsigma, \theta \alpha \rho \sigma \varepsilon \dot{\omega} \omega$. Furthermore, $\theta \alpha \rho \sigma \alpha \lambda \varepsilon \dot{\alpha} \circ, \theta \dot{\alpha} \rho \sigma \circ \varsigma, \theta \alpha \rho \sigma \varepsilon \dot{\varepsilon} \omega$ and $\theta \alpha \rho \sigma \dot{v} v \omega$ are frequently opposed to

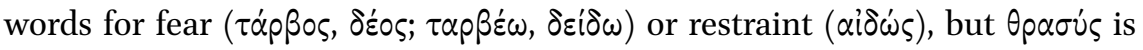
never used in such oppositions. ${ }^{118}$

In sum, the derivational connection in Homer between $\theta \alpha \rho \sigma \alpha \lambda \varepsilon$ ह́ (but not $\theta p \alpha \sigma \dot{\varsigma} \varsigma)$ and $\theta \dot{\alpha} \rho \sigma o \varsigma, \theta \alpha \rho \sigma \varepsilon \dot{\varepsilon} \omega, \theta \alpha \rho \sigma \dot{v} \omega \omega$ suggests that $\theta p \alpha \sigma \dot{\varsigma} \varsigma$ is a poetic archaism.

116 I disagree with Chantraine's claim ( $D E L G$ s.v. Өd́poos) that the original root meaning is 'to be confident'.

117 Pace Lamberterie (1990: 85o), who thinks that $\theta$ paris, with the exception of Od. 10.436, always has a positive nuance in Homer. Cf. also Meissner (2006: 71).

118 For Thucydides, Huart (1968: 426) reached the same conclusion concerning $\theta \dot{\alpha}$ poos and $\theta \alpha p \sigma \varepsilon ́ \omega:$ :toujours $\theta$ ap $\varepsilon \hat{\imath} \nu$ est en rapport direct avec l' action", and "la confiance s' oppose ainsi à l' appréhension et cette opposition, assez souvent implicite, est parfois clairement formulée". 
The use of $\theta \rho \alpha \sigma \nu$ - as a first compound member corresponding to both $\theta \alpha \rho \sigma \alpha-$

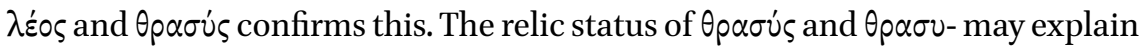
why their root was not adapted to $\theta \alpha \rho \sigma-$.

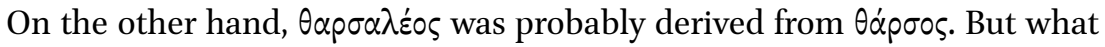

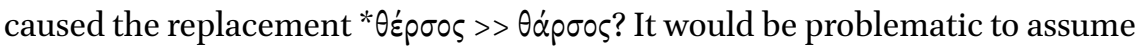
that the vocalism of $\theta p \alpha \sigma u ́ \varsigma$ was responsible, as one expects analogical influence to reduce the number of different root shapes, not to increase them. Therefore, the root vowel of $\theta \dot{\alpha} p \sigma o \varsigma$ must have been introduced from a different form, preferably from an adjective. ${ }^{119}$ We must now pose the question: is it possible that an earlier stage of Ionic-Attic had an adjective * $\theta \alpha$ oús? This would immediately account for the vocalism of $\theta \dot{\alpha} \rho \sigma o \varsigma$ and for the vowel slot of the factitive verb $\theta \alpha \rho \sigma u ́ v \omega$ in one time (cf. section 4.2.3). Before further discussing this issue, let us first consider the situation in Classical Greek.

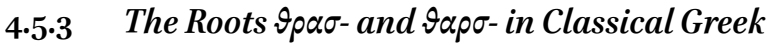

The attested formations and the distribution of the allomorphs $\theta p \alpha \sigma$ - and $\theta \alpha \rho \sigma-$ in Classical Greek are listed in Table 5 (on the following page). It distinguishes Ionic from Attic, and poetic forms from prose forms.

In Classical Greek, the allomorph $\theta p \alpha \sigma$ - is no longer limited to the forms $\theta p \alpha-$ $\sigma u ́ \varsigma$ and $\theta p \alpha \sigma u-:$ we also find the forms of comparison $\theta p \alpha \sigma \dot{\tau} \tau \varepsilon \rho \circ \varsigma, \theta p \alpha \sigma u ́ \tau \alpha \tau o \varsigma$, a denominative verb $\theta p \alpha \sigma \dot{v} v \omega$, and an abstract $\theta p \alpha \dot{\sigma o s}$. Thus, unlike Homeric Greek, the Classical language has the variants $\theta p \alpha \sigma u v v \omega \sim \theta \alpha p \sigma o ́ v \omega$ (Attic $\theta \alpha p$ -

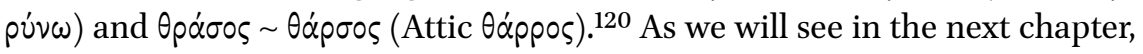
the situation for $x p \alpha \tau-\sim x \alpha \rho \tau$ - is exactly the reverse: doublets $x p \alpha \tau \varepsilon p o ́ s \sim x \alpha \rho \tau \varepsilon-$

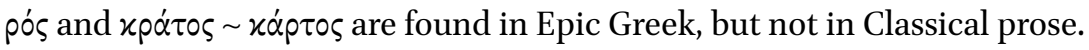

The alternation $\theta \rho \alpha \sigma-\sim \theta \alpha \rho \sigma$ - in Classical Greek reflects a phenomenon of the spoken language, while that between $x p \alpha \tau$ - and $x \alpha \rho \tau$ - in Homer belongs to the artificial language of epic. In Homer the alternation is utilized for metrical purposes, but in Classical Attic the two roots $\theta p \alpha \sigma$ - and $\theta \alpha \rho \sigma$ - are semantically distinct. As is well-known, ${ }^{121}$ Attic prose generally makes a distinction between

119 I have played with the idea that $\theta \alpha p \sigma \varepsilon$ ' $\omega$, which could well be an inherited 'stative' verb, directly reflects PGr. ${ }^{*} t^{h} r s-\bar{e}$ - and, after its vocalization, influenced the vocalism of $\theta \dot{\alpha}$ p oos. Although such a scenario is possible, I see no clear way to rigorously prove it at present. Moreover, the earlier existence of an adjective * $\theta \alpha$ poú must be posited in any case: see below.

120 Excepting the one-off instance of $\theta p \alpha \dot{\sigma} \sigma \varsigma$ in Homer, see above. In the remainder of this chapter, I will refrain from citing the Attic forms with their proper dialectal outcome -ppand refer to them only in the form with $-\rho \sigma-$.

121 See Lamberterie (1990: 849-859), and also Huart (1968: 426-431), with a special focus on Thucydides; for a concise discussion, see Meissner (2006: 70-71). 
TABLE $5 \quad \theta p \alpha \sigma-v s . \theta \alpha \rho \sigma-$ in Classical Greek prose and poetry

Өp $\alpha \sigma$ - 'bold, brave, reckless' $\quad \theta \alpha \rho \sigma$ - 'courageous, assertive'

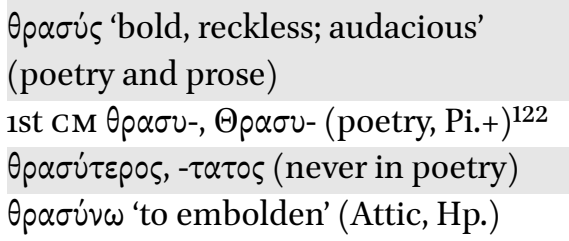

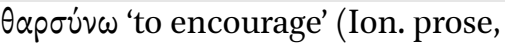

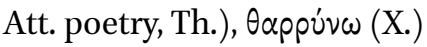

$\theta \alpha p p \alpha \lambda \varepsilon \dot{o s}$ 'self-assured, assertive, con-

fident; audacious' (Attic prose; $\theta \alpha \rho \sigma$ -

in Th., Hp. and poetry)

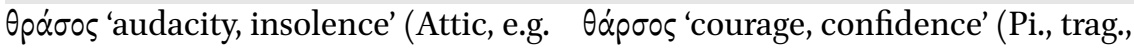
Ar., X., Pl.; never in Ionic)

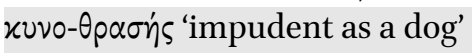

$(\mathrm{A} .)^{123}$

Hdt., Th., Pl.), Att. Od́ppos (X., Pl.)

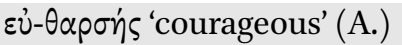

$\theta \alpha \rho \sigma \varepsilon ́ \omega($ Att. $\theta \alpha p p \varepsilon ́ \omega)$ especially in

impv. Oáppeı 'hold on!'

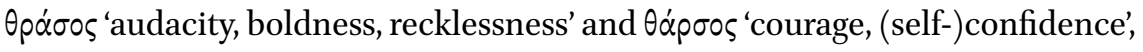
and also between $\theta p \alpha \sigma i v \omega \omega$ 'to embolden' and $\theta \alpha \rho \sigma \dot{v} v \omega$ 'to encourage, give confidence.' ${ }^{124}$ Generally speaking, this distinction is respected in Classical poetry,

122 In the extant Odes of Pindar, we find 14 compounds with $\theta$ parv- (including $7 \times$ a proper name), as against 7 attestations of the adjective $\theta p \alpha \sigma u \varsigma$. Names in $\Theta p \alpha \sigma v-$ are common in inscriptions and compete with names in $\Theta \varepsilon p \sigma t-$ (for an outdated overview, see Bechtel 1917: 207 and 211-213). The latter form also occurs in the appellative compound $\theta \varepsilon p \sigma-\varepsilon \pi \eta^{\prime} s$ 'with audacious words' (in Bacchylides). The distribution between $\theta \varepsilon \rho \sigma \mathrm{l}$ - and $\theta \rho \alpha \sigma \nu$ - was probably metrically conditioned (see above); names in $\Theta \alpha \rho \sigma \nu$ - and $\Theta \circ \rho \sigma \nu$ - are found only in certain West Greek dialects and Arcadian.

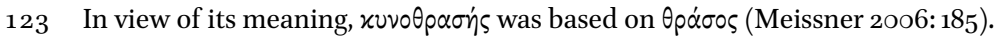

124 This semantic distinction has generally been interpreted as a difference between pejora-

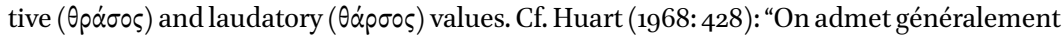

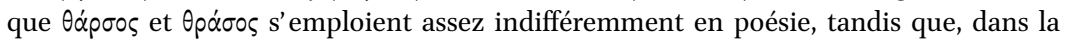
prose, $\theta \dot{\alpha} p \sigma o \varsigma$ est utilisé de préférence en bonne part, et $\theta p \alpha \dot{\sigma} \sigma \varsigma$ en mauvaise part." As Meissner (2006: 71) formulates, "The negative connotation [of $\theta \rho \alpha \sigma$-] becomes more frequent in Attic, and as early as in tragedy the meaning 'arrogant', 'audacious' prevails (...). Thus, $\theta p \alpha$ -

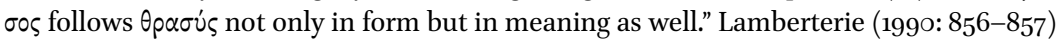
argues that the pejorative connotation may have developed, in particular, in the frequent use of $\theta p a \sigma u ́ \varsigma$ qualifying impudent words. Yet, as Huart (1968) convincingly shows, this 
too, even if there are some instances where $\theta \rho \alpha \sigma$ - is used instead of expected $\theta \alpha \rho \sigma-$, perhaps for metrical reasons. ${ }^{125}$ It is plausible that $\theta p \alpha \dot{\sigma o s}$ and $\theta p \alpha \sigma o ́ v \omega$ were productively created to the old adjective $\theta p \alpha \sigma u ́ \varsigma$ as an adjectival abstract and factitive verb, respectively.

For $\theta p \alpha \sigma$ is, the Homeric meaning 'bold, daring' continues to be the normal

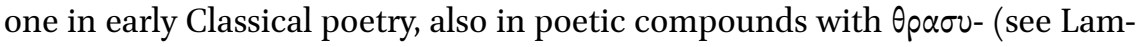
berterie 1990: 851). In Classical prose the predominant meaning becomes 'auda-

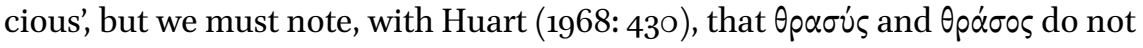
have an exclusively pejorative meaning in Thucydides. ${ }^{126}$ This does not imply,

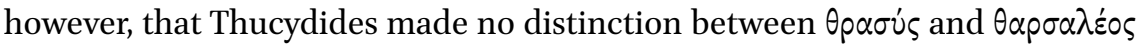
(as Huart claims): $\theta \rho \alpha \sigma u ́ \varsigma$ means 'bold; reckless' as against $\theta \alpha \rho \sigma \alpha \lambda \varepsilon \dot{\varepsilon} \circ \varsigma^{\prime}$ 'confident, self-assured.' ${ }^{127}$

Both Ionic and Attic retain $\theta \alpha \rho \sigma \dot{v} v \omega$ (already Homeric), but we also find $\theta \rho \alpha-$

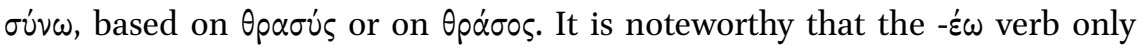
appears in the form $\theta \alpha \rho \sigma \varepsilon \omega$ 'to gain courage; hold on'; the stative-inchoative verb corresponding to $\theta \rho \alpha \dot{\sigma} \sigma \varsigma$ was not * $\theta p \alpha \sigma \varepsilon \dot{c} \omega$, but expressed by means of the middle of the factitive, $\theta$ parúvor al 'to be(come) bold or audacious'. Thus, the only old verbs are $\theta \alpha \rho \sigma \dot{v} v \omega$ and $\theta \alpha \rho \sigma \varepsilon \omega ; \theta p \alpha \sigma u ́ v \omega$ is a more recent creation. This means that Homeric $\theta \alpha \rho \sigma \dot{v} \omega \omega$ is not a metrical replacement of a vernacular

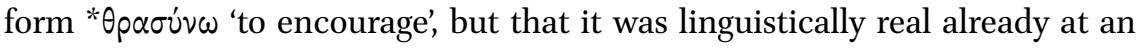
early date. In view of the difference in root vocalism, we may conclude with some confidence that $\theta \alpha \rho \sigma u ́ v \omega$ was not directly derived from $\theta p \alpha \sigma u ́ s$. The deriva-

distinction between pejorative and laudatory uses does not hold for Thucydides. On the other hand, Huart goes too far when he concludes that Thucydides made no distinction at all between the two forms. In my view, Thucydides observes a difference between $\theta \rho \dot{\alpha}-$ oos 'boldness, audacity' (frequently, but not necessarily, with the connotation of surplus: 'recklessness'), whereas $\theta \dot{\alpha}$ poos means 'confidence, assurance' (either justified or unjustified: see Huart 1968: 427).

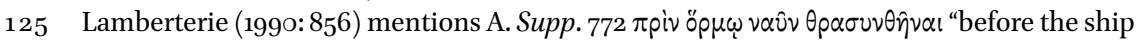
has reached a safe haven", where one would expect a form in $\theta \alpha \rho \sigma-$. It is perhaps on the

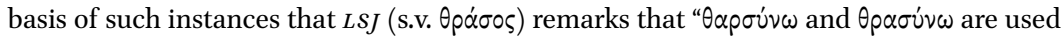
indifferently", but that clearly goes too far.

126 About $\theta p \alpha \sigma u ́ \varsigma$, Huart (1968: 430) remarks: “... chez les prosateurs postérieurs à Thucydide, le mot est généralement de valeur péjorative: Thucydide, lui, reste fidèle à l'usage ancien-celui de la poésie-où le terme est pris en bonne, ou en mauvaise part." Herodotus (7.49) also attests the meaning 'bold' without any negative connotations.

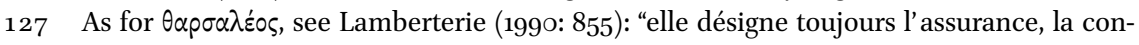
fiance en soi, par opposition à la crainte". That $\theta \alpha p \sigma \alpha \lambda \varepsilon \dot{\varepsilon} \circ$ is semantically distinct from

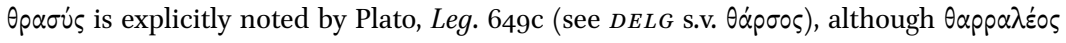

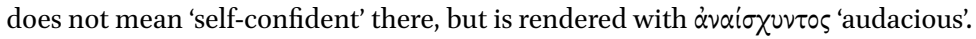


TABLE 6 The oldest distribution of the root shapes $\theta \rho \alpha \sigma-$ and $\theta \alpha \rho \sigma-$

\section{Archaic forms and Innovative forms and Innovative forms and meanings meanings (Homer) meanings (Attic)}

\begin{tabular}{|c|c|c|}
\hline 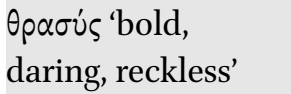 & 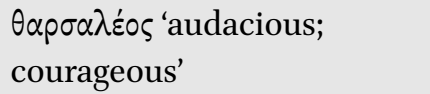 & 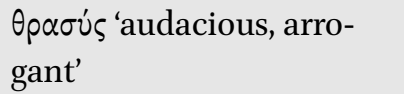 \\
\hline Өápoos 'persistence' & Oápoos 'courage, confidence' & 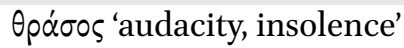 \\
\hline \multicolumn{3}{|c|}{$\theta \alpha \rho \sigma \varepsilon ́ \omega$ 'persevere' } \\
\hline & $\theta \alpha \rho \sigma u ́ v \omega$ 'give courage' & 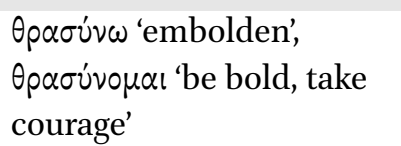 \\
\hline
\end{tabular}

tion of $\theta \alpha p \sigma u ́ v \omega$ probably took place before the vocalization of ${ }^{*} r$, and before the ancestor of $\theta \alpha p \sigma \alpha \lambda \varepsilon$ ś $\zeta$ ousted that of $\theta p \alpha \sigma i \varsigma$.

In sum: in Homer $\theta p \alpha \sigma u$ s retains its archaic meaning 'bold, reckless'; it did not take part in the semantic development to 'courageous, self-assured' that $\theta \alpha \rho \sigma \alpha \lambda \varepsilon \dot{\varepsilon} \circ, \theta \alpha \rho \sigma \delta v \omega$ and other derivations with $\theta \alpha \rho \sigma$ - had already undergone in Homer. In Classical Greek, $\theta p \alpha \sigma u ́ s$ further specializes in pejorative meanings like 'audacious; arrogant, insolent' and serves as the basis for new derivations:

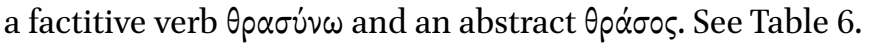

\subsubsection{Reconstruction}

Let us now review the arguments for positing an older adjective * $\theta \alpha \rho \sigma u ́ \varsigma$.

First of all, the shape of the factitive verb $\theta \alpha p \sigma u v \omega$ seems to presuppose a base form * $\theta$ apovis for the adjective. ${ }^{128}$ Against this, both Tucker (1990) and Strunk (1975) have objected that $\theta$ apoúvw may have been derived from the abstract $\theta$ ápoos already in Homer. However, we have seen (section 4.2.3) that the basis for this derivation, as early as Homer, is very slim. The main question

128 This was first proposed by Chantraine ( $D E L G$, s.v. $\theta \dot{\alpha} \rho \sigma o \varsigma)$ : "Le verbe dénominatif confirmerait l'existence de *$\theta \alpha \rho \sigma u ́ \varsigma$ et se présente sous deux formes: $\theta \alpha \rho \sigma u ́ v \omega$ (att. $\theta \alpha p p-$ ) «encourager, donner confiance», etc. (Hom., ion.-att., etc.) et $\theta p \alpha \sigma u ́ v \omega$ «encourager», qui se dit généralement d'une audace imprudente ou impudente (Aesch. Ag. 222, Th. 1.142), surtout employé au passif et au moyen, le plus souvent au mauvaise part, cf. Ar. Gren. 846, etc." Although I concur with Chantraine concerning the priority of * $\theta \alpha p \sigma \dot{s}$, I disagree with his claim that * $\theta \alpha \rho \sigma \dot{\varsigma} \varsigma$ and $\theta \rho \alpha \sigma \dot{\varsigma} \varsigma$ were simply doublets: “... la forme [ $\theta \rho \alpha \sigma \dot{\varsigma} \varsigma]$ pouvant être analogique de $\theta \alpha \rho \sigma u ́ \varsigma$ (attesté en composition) qui présente le traitement - $\alpha p$ - de * $r$, $\theta$ Épбos, etc. (...)." For this, Chantraine refers to Lejeune (1972), who ascribes the double reflex of ${ }^{*} r$ to liquid metathesis. 
is: how did the derivational pattern originate which links factitives in -v́vw to

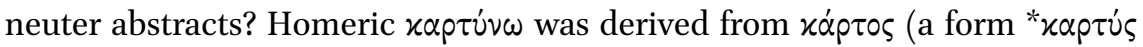
never existed), but this derivation presupposes the existence of a model. Given the absence of alternatives, it is attractive to think that the pair $\theta \alpha \rho \sigma i v \omega: \theta \alpha$ p $\sigma 0 \varsigma$ was pivotal in the emergence of the new derivational pattern, i.e. that the original base form * $\theta \alpha \rho \sigma \dot{\varsigma} \varsigma$ of $\theta \alpha \rho \sigma \dot{v} \omega \omega$ was lost before our first attestations. ${ }^{129}$ This

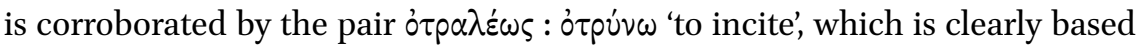
on $\theta \alpha \rho \sigma \alpha \lambda \varepsilon \dot{\varepsilon} \varsigma$ : $\theta \alpha \rho \sigma \sigma \dot{v} \omega$ 'to encourage'.

Secondly, except for the fact that $\theta p a \sigma u s$ is actually attested, there is every reason to believe that * $d^{h} r s-u$ - would indeed have resulted in * $\theta \alpha \rho \sigma$ v $\varsigma$, whether its vocalism arose by analogy with the full grade root ${ }^{*} d^{h}$ ers- or by regular sound

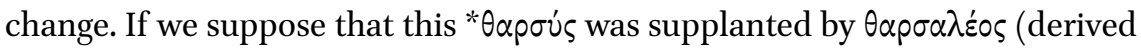
from $\theta \alpha \dot{\alpha} \rho \sigma \varsigma \varsigma)$, all pieces suddenly fall into place. First, ${ }^{*} \theta \alpha \rho \sigma u ́ \varsigma$ (perhaps assisted

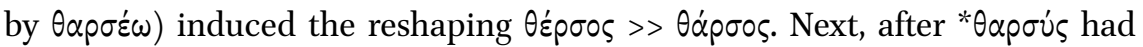
fallen in disuse and was replaced by $\theta \alpha \rho \sigma \alpha \lambda \varepsilon$ Éos, a new derivational pattern $\theta \dot{\alpha} \rho-$ $\sigma \circ \varsigma \rightarrow \theta \alpha \rho \sigma \dot{v} \omega \omega$ emerged.

If this account is accepted, it still remains to account for the form $\theta p \alpha \sigma u$ s. Its deviant root shape can only be explained as the regular phonetic reflex of a preform * ${ }^{h}{ }_{r} r s u ́$-. It can be excluded, however, that both $\theta p \alpha \sigma u ́ \varsigma$ and ${ }^{*} \theta \alpha \rho \sigma u ́ \varsigma$ resulted from the same paradigm in the same dialect. In my view, a promising solution is that $\theta p \alpha \sigma \dot{s} \varsigma$ has a special epic reflex of * $r$; it was borrowed from epic into the spoken language with its archaic meaning 'bold, intrepid' (whence 'audacious; reckless'). It would not be unexpected if an adjective meaning 'bold, daring, reckless' was borrowed from heroic poetry. This scenario will be bolstered with further arguments in chapter 6 , where I propose that - $\rho \alpha$-was a regular outcome of what I shall call 'Epic * ${ }^{\prime}$ ', i.e. * ${ }_{0} r$ which was retained in Epic Greek longer than in the vernaculars and then underwent its proper vocalization.

Such a suggestion may appear random at this point, especially since the isolated adjective $\tau \alpha \rho \varphi \varepsilon ́ \varepsilon \varsigma$ (with its reflex - $\alpha \rho-$ ) is also limited to Epic Greek. In order to effectively counter this objection, we must analyze more material. I

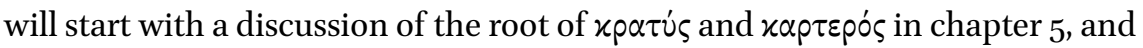
then turn to the Homeric evidence for muta cum liquida scansion in forms with - $\rho \alpha$ - or - $\rho$ - in chapter 6 . At this point, we may already take into account the fact that $\theta p \alpha \sigma \dot{s} \varsigma$ occurs in Homeric material that is clearly traditional: cf. the

129 The alternative would be to assume that the expected form * $\theta p \alpha \sigma \dot{v} \omega \omega$ was replaced by $\theta \alpha p$ -

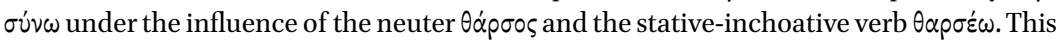
is unlikely because (i) usually the root shape of the adjective (as the basic form for derivation) wins out, and (ii) as long as the adjective continued to exist in the shape $\theta p \alpha \sigma u ́ s$, a reshaping * $\theta p \alpha \sigma u ́ v \omega ~>>\theta \alpha \rho \sigma u ́ v \omega$ would be unlikely. 


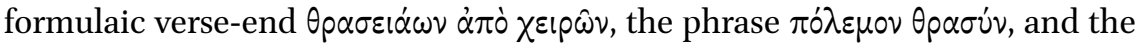
metrically governed alternation between $\theta \rho \alpha \sigma \nu$ - and $\theta \varepsilon \rho \sigma-$ as first compound members and in names.

\subsection{Conclusions}

Starting out from a discussion of the expected ablaut grades in PIE and ProtoGreek 'Caland' formations, we have seen that many forms with - $\alpha \rho-(-\alpha \lambda-)$ and $-\rho \alpha-(-\lambda \alpha-)$ cannot be used as evidence for the regular reflex of ${ }^{*} r$ or ${ }^{*}$. This holds for most forms belonging to the following categories:

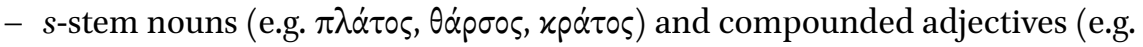
$\left.-\pi \lambda \alpha \tau \eta^{\prime},-\theta \alpha \rho \sigma \zeta^{\prime},-\varkappa \rho \alpha \tau \dot{\eta} \varsigma\right)$; these originally had a full grade root and secondarily introduced the zero grade reflex of a simplex adjective;

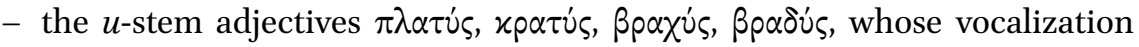
may have been influenced by the full grade slot of the root (as in the forms of comparison);

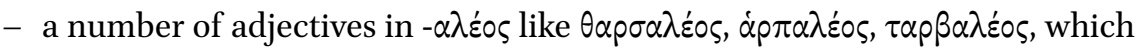
may owe their vocalism to earlier $s$-stem abstracts or stative verbs.

The so-called 'stative' verbs in - $\varepsilon$ (e.g. $\left.x p \alpha \tau \varepsilon^{\prime} \omega, \theta \alpha \rho \sigma \varepsilon \dot{\varepsilon} \omega, \tau \alpha \rho \beta \tilde{\varepsilon} \omega\right)$ play an ambiguous role. Etymologically, they have a zero grade root, but synchronically they have derivational ties with $s$-stem nouns and adjectives, witness the fact that

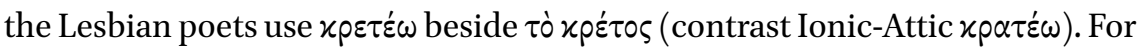
this reason a form like $\theta \alpha p \sigma \varepsilon \dot{c} \omega$ is difficult to use for the purpose of reconstruction, although it may in theory display the direct reflex of zero-grade ${ }^{*} t^{h_{r} s-\text {. In }}$ the case of $\tau \alpha \rho \beta \varepsilon \dot{\varepsilon} \omega, \tau \dot{\alpha} \rho \beta \eta \sigma \alpha$ it is quite plausible that its aorist directly reflects ${ }^{*} \operatorname{trg}^{w}-\bar{e}-s-$.

Returning to the $u$-stem adjectives, we have seen that three forms show the regular vocalization of a syllabic liquid. PIE * $m l d-u$ - 'soft' is reflected in the plural form $\beta \lambda \alpha \delta \varepsilon \hat{\zeta}$, attested as a gloss in Hesychius. The factitive verb $\alpha \mu \alpha \lambda \delta \dot{\delta} v \omega$ 'to corrode' is a denominative based on another reflex of * $m_{0} l d-\tilde{u}^{-}$, " $\dot{\alpha} \mu \alpha \lambda \delta \nu$ - with secondary $\dot{\alpha}$-, whose vocalization was influenced by the full grade *meld- (cf. $\mu \dot{\varepsilon} \lambda \delta \delta \mu \alpha \iota$ 'to melt'). It is uncertain how this divergence is to be explained (possibly a dialectal difference). For further evidence for ${ }^{*} l>-\lambda \alpha-$, see chapter 10.

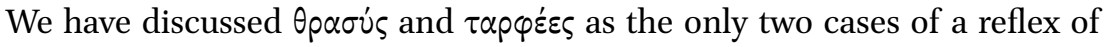
${ }^{*} r$ for which analogical reshaping is excluded. Ex hypothesi, the two reflexes

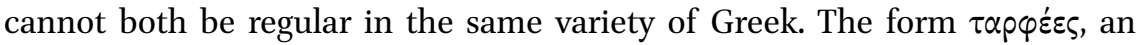
archaic plurale tantum in Homer, with an aberrant accentuation of the feminine $\tau \alpha \rho \varphi \varepsilon ı \alpha$, shows the regular Proto-Ionic reflex. The cognate adjective $\tau p \alpha-$

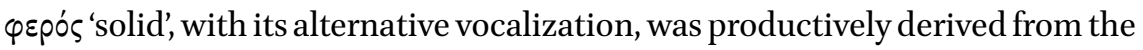




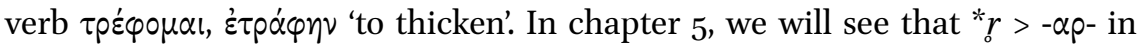

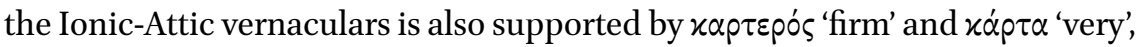

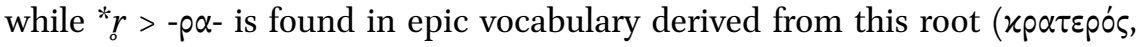

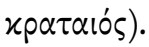

This leaves us with the task of accounting for $\theta p \alpha \sigma u$ s. Excepting some cases in poetry, there was never a free allomorphy between $\theta \rho \alpha \sigma-$ and $\theta \alpha \rho \sigma-$, neither in Homeric Greek nor in Classical prose. I have argued that an alternative form * $\theta \alpha$ poús once existed: this underlies the factitive verb $\theta \alpha \rho \sigma u ́ v \omega$, and crucially, it would be hard to understand why and how the allomorph $\theta \alpha \rho \sigma$ - spread through all other derivatives (replacing $\theta \varepsilon \rho \sigma-)$ if $\theta p \alpha \sigma u$ s had always been the current form of the adjective. The adjective corresponding functionally to $\theta \dot{\alpha} p \sigma o s$ and $\theta \alpha \rho \sigma u ́ v \omega$ is $\theta \alpha \rho \sigma \alpha \lambda \varepsilon \dot{\sigma} \circ$ (not $\theta \rho \alpha \sigma u \varsigma$ ), and it would make good sense if * $\theta \alpha \rho \sigma \dot{\zeta} \varsigma$ was

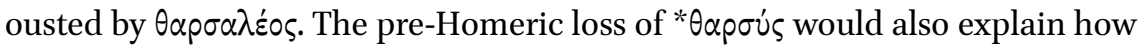
the derivation of factitives in - $v \omega \omega$ from $s$-stem neuter abstracts started (namely from the pair $\theta \alpha \rho \sigma o v v \omega: \theta \alpha$ p $\sigma \circ \varsigma)$.

In view of these considerations, I suppose that * $\theta \alpha \rho \sigma$ ¿́ is the regular ProtoIonic reflex of * ${ }^{*}{ }^{h} r s u$, and that $\theta$ parús did not develop in spoken varieties of Ionic-Attic. In chapter 6 , I will further elaborate the idea that its reflex - $\rho \alpha$-arose within the prehistory of Epic Greek. 